\title{
A DFT Analysis on Antioxidant and Antiradical Activities from Anthraquinones Isolated from the Cameroonian Flora
}

\author{
Judith Caroline Ngo Nyobe, ${ }^{1}$ Laurent Gael Eyia Andiga, ${ }^{2}$ Désiré Bikele Mama (iD, 1 \\ Baruch Ateba Amana $\mathbb{D}^{1},{ }^{1}$ Joseph Zobo Mfomo, ${ }^{3}$ Toze Flavien Aristide Alfred, \\ and Jean Claude Ndom ${ }^{1}$ \\ ${ }^{1}$ Department of Chemistry, Faculty of Science, University of Douala, P.O. Box 24157, Douala, Cameroon \\ ${ }^{2}$ Department of Inorganic Chemistry, Faculty of Science, University of Yaoundé I, P.O. Box 812, Yaoundé, Cameroon \\ ${ }^{3}$ Department of Forestry and Wood Engeneering, Advances Teachers Training College for Technical Education, \\ University of Douala, P.O. Box 24157, Douala, Cameroon
}

Correspondence should be addressed to Désiré Bikele Mama; bikelemama@yahoo.fr

Received 29 December 2018; Revised 23 February 2019; Accepted 5 May 2019; Published 24 June 2019

Academic Editor: Arturo Espinosa Ferao

Copyright $(92019$ Judith Caroline Ngo Nyobe et al. This is an open access article distributed under the Creative Commons Attribution License, which permits unrestricted use, distribution, and reproduction in any medium, provided the original work is properly cited.

The present work is devoted to the exploration antioxidant and antiradical activity of twenty anthraquinones isolated from the Cameroonian flora at B3LYP/6-311++G(d,p) level of theory using the B3LYP/6-31 + G(d,p) geometrical data as geometry optimization starting points. The single electron transfer mechanism has been adopted to examine both biological activities. The classification of the antiradical profile to integrate the electrodonating power $\left(\omega^{-}\right)$, electroaccepting power $\left(\omega^{+}\right)$, donor index $\left(R_{\mathrm{d}}\right)$ and acceptor index $\left(R_{\mathrm{a}}\right)$ has been performed using the donor-acceptor map (DAM). The antioxidant and radical powers of compounds analyzed have been compared to that of two classical vitamins (vitamin $\mathrm{C}$ and gallic acid). The stability of each anthraquinone derivative of the molecular library has been developed according to thermodynamic and kinetic concepts. The global reactivity descriptors (GRDs; electrophilicity index $(\omega)$, electronegativity $(\chi)$, global softness $(S)$, and global hardness $(\eta)$ ) have been used to analyze the reactivity. The topological analysis of optimized structures indicates that the strength of the hydrogen bonds formed is situated between 44.205 and $52.001 \mathrm{~kJ} / \mathrm{mol}$. Our B3LYP results reveal that 3-methoxy-1-vismiaquinone (in a configuration without hydrogen bond) exhibits the best antioxidant capacity in gas phase. A comparison between antioxidant performance of molecules examined and that of classical vitamins (gallic acid, caffeic acid, ferulic acid, and ascorbic acid (vitamin C)) displayed the fact that the single electron transfer (SET) mechanism is more prominent for compounds of the molecular library analyzed. In the same vein, the antiradical behaviors of anthraquinone derivatives have shown to be higher than that of gallic acid and vitamin $\mathrm{C}$ in gas phase and water. The 5,8-dihydroxy-2-methylantraquinone structure in a configuration bearing one hydrogen bond has been found to be the best antiradical of the series in aqueous solution.

\section{Introduction}

Lipids are significant function component role in food through their influence of texture cooking and that of waterholding capacity (WHC). However, the flavor color, texture, and nutritional value of food are frequently diminished as the result of lipid deterioration during storage [1]. The oxidation of food lipid, known as oxidative rancidity, is one of the major deteriorative and quality affecting reactions [2]. Oxidative rancidity is initiated by oxygen free radicals (as reactive oxygen species (ROS)) that result from the food sourness, the rootedness oil, and most of industrial product aging. The main free radicals are superoxide radicals (SOR), hydroxyl radical (OHR), alkoxyl radical (AR), peroxyl radical (PR) and nitric oxide radical (NOR) [2]. Butylated hydroxytoluene (BHT) and butylated hydroxyanisole (BHA) are extensively used as antioxidants in order to reduce the harm caused by free radicals. However, these antioxidants will be unfavorable to be used in the fields of foods and health products because they would induce toxicity in animal body at longtime [3]. An excess of free radicals provokes oxidation stress due to an imbalance between 
production of ROS and antioxidant defenses [4]. This oxidation stress leads to the damage of cellular proteins, membrane lipids, and nucleic acids. This process has been implicated in the pathogenesis of various diseases, including coronary heart diseases and some forms of cancer [5] like Alzheimer's disease, Parkinson's disease, and schizophrenia.

Due to the toxicity of these classical synthetic antioxidants (BHT and BHA), many attempts to block this oxidative stress using natural food plants have been reported to make free radicals for destruction. For instance, many authors have shown the ability of flavonoids to trap the radicals through the hydrogen transfer process: the reduction potentials of some amino-9,10-anthraquinone derivatives using computational electrochemistry method [6] performed by Shamsipur et al. can be cited. Furthermore, an extensive study of the hormonal activity of sesquiterpene isolated from Ferula hermonis and the high marketability of the dietary herbal products containing Ferula hermonis extract claiming a sexual function enhancement effect have been published $[7,8]$. In the same vein, anthraquinone derivatives isolated from root of madder plant (Rubia tinctorum $\mathrm{L}$ ) have displayed an exceptional antioxidant activity that explained their capacity to protect foods against the oxidative damage [9]. Formerly, Malterud et al. have studied the correlation between the in vitro radical scavenging activity of anthraquinones and the antioxidant capacity in hepatocytes [10]. These authors have shown that aloe-emodin $\left(\mathrm{IC}_{50} 65 \pm 3 \mu \mathrm{mol} / \mathrm{l}\right)$ presented the highest antioxidant capacity of the series of seven anthraquinone derivatives analyzed (alizarin, chrysophanol, danthron, etc.). Ozbakir Işin has observed a striking similarity between experimental antioxidant activity of these molecules and theoretical data obtained from quantum chemistry approach [11]. The impact of the geometrical structure of hydroxyanthraquinone on the antioxidant mechanisms has been experimentally illustrated by Markovic et al. [12]. Investigations of quantitative tools to estimate antiradical activity and its mechanisms through a combination of an experimental assessment and a computational prediction of delphinidin (Dp), pelargonidin $(\mathrm{Pg})$, and malvin (Mv) have put the emphasis on the energy requirements for reactions involved [13]. The survey of the literature demonstrates that the experimental or theoretical examination of antiradical or antioxidant activities of anthraquinone derivatives is limited on restricted series of molecules without any specific comparison of these activities to those of classical vitamins (vitamin C, vitamin E, gallic acid, etc). The aim of the present study is to predict the antiradical activity of twenty anthraquinones isolated from Cameroonian flora through computational approaches based on the two electron transfer mechanisms:

$$
\begin{gathered}
\mathrm{RXH} \longrightarrow \mathrm{RXH}^{+}+e^{-} \\
\mathrm{RXH}^{-} \longrightarrow \mathrm{RXH}+e^{-}
\end{gathered}
$$

From thermodynamic energy of reactions (1)-(2), the global descriptive parameters such as electrophilicity index $(\omega)$, electronegativity $(\chi)$, global softness $(S)$, and global hardness $(\eta)$ have also been calculated. The donor-acceptor map (DAM) has also been built.

\section{Computational Details}

The geometry optimizations of anthraquinones have been initially performed at B3LYP/6-31 $+\mathrm{G}(\mathrm{d}, \mathrm{p})$ level of theory in gas phase and water using the Gaussian 09 software [14]. The reoptimization of each B3LYP/6-31 + G(d,p) optimized structure obtained has been done at B3LYP/6-311++G(d,p) level in gas phase and water. For each molecule, geometry optimization was followed by the vibrational frequency calculations. The solvent effects were taking into account using Integral Formalism of Polarized Continuum Model (IEF-PCM).

The quantum mechanics atom in molecule (QMAIM) theory was then performed using B3LYP/6-311++G(d,p) wavefunction to investigate the bonding properties of optimized structures. The bonding properties and the analysis of bond critical points are specified through the investigation of chemical bonding topology. This QMAIM investigation using the Multiwfn program [15] was done to analyze the nature and the strength of hydrogen bond interactions in optimized structures. The indicators of bonding interactions are electron densities $\rho(r)$ and its Laplacian $\nabla^{2} \rho(r)$ evaluated at bond critical points (CP). The total number of these CPs obtained is in accordance with the Poincare-Hopf rule [16]. The density of the total energy of electrons $(H)$ defined as the sum of the Lagrangian kinetic electron density $(G)$ and the potential electron density $(V)$ at bond critical points (BCPs) was estimated:

$$
H_{\mathrm{BCP}}=G_{\mathrm{BCP}}+V_{\mathrm{BCP}},
$$

where $G_{\mathrm{BCP}}$ and $V_{\mathrm{BCP}}$ are, respectively, defined as follows:

$$
\begin{gathered}
G_{\mathrm{BCP}}=\frac{3}{10} 3(\pi)^{2 / 3} \rho(r)^{5 / 3}+\frac{1}{6} \rho(r), \\
V_{\mathrm{BCP}=(\hbar / 4 m) \nabla^{2} \rho(r)-2 G_{\mathrm{BCP}} .}
\end{gathered}
$$

The interatomic interaction energy denoted $E_{\text {int }}$ in isolated ligands and in complexes was predicted by Espinosa approach [17]:

$$
E_{\text {int }}=\frac{1}{2} V_{\mathrm{BCP}} .
$$

The ionization potential (IP(I)) and electron affinity (EA (A)) were descriptors which was calculated as the energy change of the single electron transfer (SET) mechanisms (1) and (2), respectively (reaction (1) in equation (6)) and (reaction (2) in equation (7)): energy difference between the product system and the reactant system is defined as proposed by Borges et al. [18, 19].

$$
\begin{gathered}
\mathrm{IP}=I=E_{T}\left(\mathrm{RXH}^{+}\right)-E_{T}(\mathrm{RXH}) \\
\mathrm{EA}=A=E_{T}(\mathrm{RXH})-E_{T}\left(\mathrm{RXH}^{--}\right)
\end{gathered}
$$

where $\mathrm{RXH}, \mathrm{RXH}^{+}$, and $\mathrm{RXH}^{-}$represent neutral molecules, cationic radicals, and anionic radicals, respectively. These two terms $I$ and $A$ are useful to define the measurement of global reactivity descriptors ((electronegativity $(\chi)$, global hardness $(\eta)$, global softness (S), and electrophilicity index $(\omega)$ ) according to Geerlings et al. [20]: 


$$
\begin{aligned}
& \chi=-\mu=-\left(\frac{\partial E}{\partial N}\right)_{\nu(r)}=\frac{1}{2}(I+A), \\
& \eta=\frac{1}{2}\left(\frac{\partial^{2} E}{\partial N^{2}}\right)_{\nu(r)}=\frac{1}{2}\left(\frac{\partial \mu}{\partial N}\right)_{\nu(r)}=\frac{1}{2}(I-A), \\
& S=\frac{1}{2 \eta} \\
& \omega=\frac{\mu^{2}}{2 \eta} .
\end{aligned}
$$

These two terms have also been used to evaluate the electrodonating $\left(\omega^{-}\right)$and electroaccepting $\left(\omega^{+}\right)$power as formulated by Gázquez et al. [21]:

$$
\begin{aligned}
& \omega^{-}=\frac{(3 I+A)^{2}}{16(I+A)^{2}}, \\
& \omega^{+}=\frac{(I+3 A)^{2}}{16(I+A)} .
\end{aligned}
$$

From the calculation of the donor $\left(R_{\mathrm{d}}\right)$ and acceptor $\left(R_{\mathrm{a}}\right)$ index developed by Martinez et al. [22] (equations (10) and (11)), the authors have built a donor-acceptor map (DAM; Figure 1):

$$
\begin{aligned}
& R_{\mathrm{d}}=\frac{\omega_{\mathrm{RXH}}^{-}}{\omega_{\mathrm{Na}}^{-}}, \\
& R_{\mathrm{a}}=\frac{\omega_{\mathrm{RXH}}^{+}}{\omega_{\mathrm{F}}^{+}},
\end{aligned}
$$

where $\omega_{\mathrm{RXH}}^{-}$and $\omega_{\mathrm{Na}}^{-}$are, respectively, the electrodonating power of colorotane sesquiterpenes (RXH) and $\mathrm{Na}$ atom, whereas $\omega_{\mathrm{RXH}}^{+}$and $\omega_{\mathrm{F}}^{+}$refer, respectively, to electroaccepting power of colorotane sesquiterpenes $(\mathrm{RXH})$ and $\mathrm{F}$ atom.

\section{Results and Discussion}

3.1. Geometrical and Topological Properties. We have formulated the molecular system (Figure 2) and divided it into three fragments: benzene cycles $\alpha$ (on the left), $\beta$ (on the centre), and $\gamma$ (on the right). The subscripts associated with the adopted name of molecular structures inserted in Figure 2 have been developed according to the following principle: subscripts (0) when the structure does not possess any hydrogen bond; subscripts (1) when one hydrogen bond is formed between hydrogen atom of hydroxyl group of benzene cycle $(\alpha)$ and ketone carried by benzene cycle $(\beta)$; subscripts (11) when one hydrogen bond is formed between hydrogen atom of hydroxyl group of benzene cycle $(\gamma)$ and ketone of benzene cycle $(\gamma)$; and subscripts (2) when the hypothesis of formation of two hydrogen bonds is considered.

Table 1 reports the bond distances and bond angles useful to characterize hydrogen bonds in various configurations adopted. A close examination of this table reveals that the geometrical features of hydrogen bond formed are characterized by $\mathbf{O}_{\mathrm{i}}-\mathbf{H} . \ldots \mathbf{O}_{2}<3 \AA$ and $\mathrm{O}_{\mathrm{i}}-\mathbf{H}$. . $\mathbf{O}_{2}$ angle $>110^{\circ}(i=6$

\begin{tabular}{|l|l|l|}
\hline $\begin{array}{l}\text { Bad acceptor } \\
\text { Bad donor }\end{array}$ & $\begin{array}{l}\text { Good acceptor } \\
\text { Bad donor } \\
\text { Good antireductant } \\
\text { The worst antiradical } \\
\text { Good antiradical }\end{array}$ \\
\cline { 2 - 3 } & $\begin{array}{l}\text { Bad acceptor } \\
\text { Good donor } \\
\text { Good antioxidant } \\
\text { Good antiradical }\end{array}$ & $\begin{array}{l}\text { Good acceptor } \\
\text { Good donor }\end{array}$ \\
\hline \multicolumn{2}{|c|}{$R_{\mathrm{a}}$} \\
\hline
\end{tabular}

FIgURE 1: Schematic representation of donor-acceptor map (DAM).

and 10). The O...H length gives an indication of the hydrogen bond strength. This hydrogen bond strength may help to understand the energy gap between different conformations of each structure [23]. The $\mathbf{O}_{6}-\mathbf{H}$. . $\mathbf{O}_{2}$ bond lengths are lower in $\mathrm{Y}_{11}$ conformers ( $\mathrm{Y}$ is the name adopted for the molecule) than in $\mathbf{Y}_{2}$ configurations. For instance, the bond distance differences calculated for D and $G$ are, respectively, 0.052 and $0.060 \AA$. This indicates that $\mathbf{O}_{6}-\mathbf{H}$. . $\mathbf{O}_{2}$ is weaker in $\mathbf{Y}_{11}$ conformers. This illustrates the importance of simultaneous formation of hydrogen bonds on each side of the $\mathrm{C}_{8}=\mathbf{O}_{2}$ ketone. In $\mathbf{Y}_{2}$ configuration, our results show that $\mathbf{O}_{6}-\mathbf{H} \ldots \mathbf{O}_{2}$ bond distances is longer than $\mathbf{O}_{10}-\mathbf{H} \ldots \mathbf{O}_{2}$ homologues. For $\mathbf{C}_{2}$ and $\mathbf{F}_{2}$ conformers, the bond length differences are, respectively, about 0.019 and $0.013 \AA$. The $\mathbf{O}_{10^{-}}$ H. . . $\mathbf{O}_{2}$ interaction can therefore be considered higher than $\mathbf{O}_{6}-\mathbf{H} . . \mathbf{O}_{2}$ one. Such a fact is attributed to the nearness of the former to the substitution site $\left(\mathbf{C}_{5}\right.$ atom). The bond distances for $\mathbf{O}_{10}-\mathbf{H} \ldots \mathbf{O}_{2}$ and $\mathbf{O}_{13}-\mathbf{H}$. . $\mathbf{O}_{2}$ bonds are lightly similar due to the symmetrical position of $\mathbf{O}_{10}-\mathbf{H}$ and $\mathbf{O}_{13}-\mathbf{H}$ bonds. In $\mathbf{Y}_{0}$ conformers in gas phase, the $\mathbf{O}_{10}-\mathbf{H}$ bond distances are higher than $\mathbf{O}_{6}-\mathbf{H}$ bond length with the exception of $\mathbf{G}_{0}$ molecule in which these two bond lengths are almost identical (Figure 3). Similar observations are obtained for $\mathbf{D}_{1}$ and $\mathbf{D}_{11}$ conformers. The hydrogen atom of $\mathbf{O}_{10}-\mathbf{H}$ hydroxyl is therefore more labile than the hydrogen atom of $\mathbf{O}_{6}-\mathbf{H}$ hydroxyl. The expected values of bond dissociation energy (BDE) of $\mathbf{O}_{10}-\mathbf{H}$ are therefore lower. Contrary facts are obtained for $\mathbf{Y}_{2}$ conformers. In the whole, the hydrogen atom of $\mathbf{O}_{6}-\mathbf{H}$ hydroxyl of $\mathbf{E}_{0}$ conformer is the most labile. This is due to the fact that this hydroxyl group is near to the substituent connected to $\mathbf{C}_{4}$ atom containing two $\mathrm{C}=\mathrm{C}$ double bonds and one $\mathrm{sp}^{2}$ oxygen atom. Independently of the initial geometries adopted, the geometrical optimization of the molecule A yields a structure in which two hydrogen bonds: first one between an oxygen atom of the aldehyde group $(\mathrm{CHO})$ and the hydrogen atom of the hydroxyl group connected to the $\mathbf{C}_{3}$ atom $\left(\mathbf{C}_{3}-\mathrm{O}-\mathbf{H}\right.$. . . O: $1.580 \AA$ and $142.2^{\circ}$ ) and the second one between an hydrogen atom of the aldehyde group $(\mathrm{CHO})$ and the oxygen atom of the $\mathbf{C}_{1}=\mathbf{O}$ ketone $\left(\mathbf{C}=\mathbf{O}\right.$...H-C: $2.060 \AA$ and $\left.123.6^{\circ}\right)$. The methyl group joined to $\mathbf{C}_{5}-\mathbf{O}$ bond is orientated toward the $\mathrm{C}_{6}-\mathbf{H}$ bond. Table 1 clearly specifies the fact that the number of hydrogen bonds formed is a stability factor of the molecules 

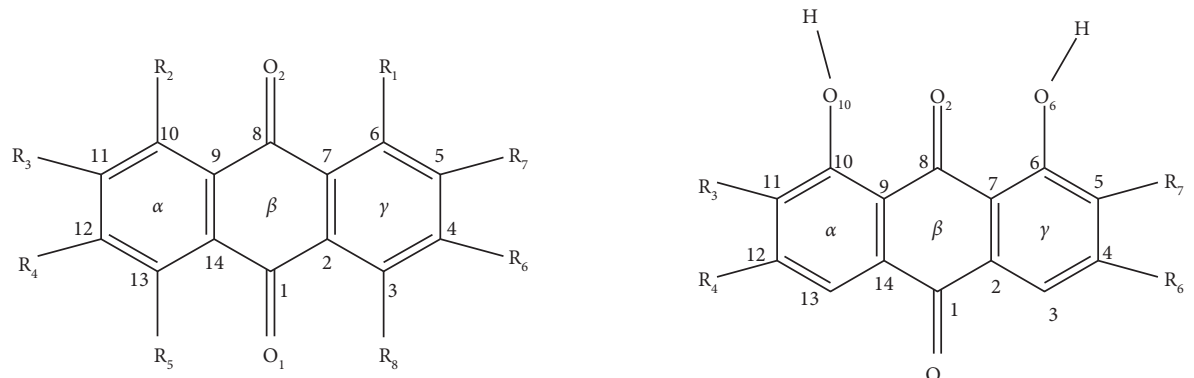

\begin{tabular}{|c|c|c|c|c|c|c|c|}
\hline & $\mathrm{R}_{1}$ & $\mathrm{R}_{2}$ & $\mathrm{R}_{3}$ & $\mathrm{R}_{4}$ & $\mathrm{R}_{5}$ & $\mathrm{R}_{6}$ & $\mathrm{R}_{7}$ \\
\hline A & $\mathrm{OCH}_{3}$ & $\mathrm{H}$ & $\mathrm{H}$ & $\mathrm{H}$ & $\mathrm{H}$ & $\mathrm{OH}$ & $\mathrm{H}$ \\
\hline B & $\mathrm{O}_{6-} \mathrm{H}$ & $\mathrm{O}_{10}-\mathrm{H}$ & $\mathrm{H}$ & $\mathrm{CH}_{3}$ & $\mathrm{H}$ & $\mathrm{OCH}_{3}$ & $\mathrm{CHCHCH}\left(\mathrm{CH}_{3}\right) \mathrm{CH}_{3}$ \\
\hline C & $\mathrm{O}_{6-} \mathrm{H}$ & $\mathrm{O}_{10-} \mathrm{H}$ & $\mathrm{H}$ & $\mathrm{H}$ & $\mathrm{H}$ & $\mathrm{H}$ & $\mathrm{CH}_{2} \mathrm{CHC}\left(\mathrm{CH}_{3}\right) \mathrm{CH}_{3}$ \\
\hline D & $\mathrm{O}_{6-} \mathrm{H}$ & $\mathrm{O}_{10-} \mathrm{H}$ & $\mathrm{H}$ & $\mathrm{CH}_{3}$ & $\mathrm{H}$ & $\mathrm{OH}$ & $\mathrm{CH}_{2} \mathrm{CHC}\left(\mathrm{CH}_{3}\right) \mathrm{CH}_{2} \mathrm{CH}_{2} \mathrm{CHC}\left(\mathrm{CH}_{3}\right) \mathrm{CH}_{3}$ \\
\hline E & $\mathrm{O}_{6-} \mathrm{H}$ & $\mathrm{O}_{10-} \mathrm{H}$ & $\mathrm{H}$ & $\mathrm{CH}_{3}$ & $\mathrm{H}$ & $\mathrm{OCH}_{2} \mathrm{CHC}\left(\mathrm{CH}_{3}\right) \mathrm{CH}_{2} \mathrm{CH}_{2} \mathrm{CHC}\left(\mathrm{CH}_{3}\right) \mathrm{CH}_{3}$ & $\mathrm{H}$ \\
\hline F & $\mathrm{O}_{6-} \mathrm{H}$ & $\mathrm{O}_{10-} \mathrm{H}$ & $\mathrm{H}$ & $\mathrm{CH}_{3}$ & $\mathrm{H}$ & $\mathrm{OH}$ & $\mathrm{H}$ \\
\hline G & $\mathrm{O}_{6-} \mathrm{H}$ & $\mathrm{O}_{10-} \mathrm{H}$ & $\mathrm{H}$ & $\mathrm{CH}_{3}$ & $\mathrm{OCH}_{3}$ & $\mathrm{H}$ & $\mathrm{CH}_{2} \mathrm{CHC}\left(\mathrm{CH}_{3}\right) \mathrm{CH}_{3}$ \\
\hline $\mathrm{H}$ & $\mathrm{O}_{6-} \mathrm{H}$ & $\mathrm{H}$ & $\mathrm{H}$ & $\mathrm{H}$ & $\mathrm{O}_{13-} \mathrm{H}$ & $\mathrm{CH}_{3}$ & $\mathrm{OCOCH}_{3}$ \\
\hline J & $\mathrm{H}$ & $\mathrm{O}_{10-} \mathrm{H}$ & $\mathrm{H}$ & $\mathrm{H}$ & $\mathrm{O}_{13-} \mathrm{H}$ & $\mathrm{CH}_{3}$ & $\mathrm{H}$ \\
\hline K & $\mathrm{H}$ & $\mathrm{H}$ & $\mathrm{H}$ & $\mathrm{H}$ & $\mathrm{H}$ & $\mathrm{CH}_{3}$ & $\mathrm{OH}$ \\
\hline L1 & $\mathrm{O}_{6-} \mathrm{H}$ & $\mathrm{O}_{10-} \mathrm{H}$ & $\mathrm{H}$ & $\mathrm{CH}_{3}$ & $\mathrm{H}$ & $\mathrm{H}$ & $\mathrm{CHCHCH}\left(\mathrm{CH}_{3}\right) \mathrm{CH}_{3}$ \\
\hline L2 & $\mathrm{H}$ & $\mathrm{O}_{10}-\mathrm{H}$ & $\mathrm{H}$ & $\mathrm{H}$ & $\mathrm{O}_{13-} \mathrm{H}$ & $\mathrm{H}$ & $\mathrm{H}$ \\
\hline M & $\mathrm{O}_{6} \mathrm{H}$ & $\mathrm{CH}_{3}$ & $\mathrm{OH}$ & $\mathrm{OH}$ & $\mathrm{H}$ & $\mathrm{OCH}_{3}$ & $\mathrm{H}$ \\
\hline $\mathrm{N}$ & $\mathrm{O}_{6-} \mathrm{H}$ & $\mathrm{CH}_{3}$ & $\mathrm{OCH}_{3}$ & $\mathrm{OCH}_{3}$ & $\mathrm{H}$ & $\mathrm{OCH}_{3}$ & $\mathrm{H}$ \\
\hline O & $\mathrm{O}_{6-} \mathrm{H}$ & $\mathrm{CH}_{3}$ & $\mathrm{H}$ & $\mathrm{OH}$ & $\mathrm{H}$ & $\mathrm{OH}$ & $\mathrm{H}$ \\
\hline P & $\mathrm{O}_{6-} \mathrm{H}$ & $\mathrm{CH}_{3}$ & $\mathrm{H}$ & $\mathrm{OCH}_{3}$ & $\mathrm{H}$ & $\mathrm{OCH}_{3}$ & $\mathrm{H}$ \\
\hline Q & $\mathrm{O}_{6-} \mathrm{H}$ & $\mathrm{O}_{10}-\mathrm{H}$ & $\mathrm{H}$ & $\mathrm{CH}_{3}$ & $\mathrm{H}$ & $\mathrm{OCH} 3$ & $\mathrm{H}$ \\
\hline $\mathrm{R}$ & $\mathrm{O}_{6-} \mathrm{H}$ & $\mathrm{CH}_{3}$ & $\mathrm{COOH}$ & $\mathrm{OCH}_{3}$ & $\mathrm{H}$ & $\mathrm{OCH}_{3}$ & $\mathrm{H}$ \\
\hline S & $\mathrm{OCH}_{3}$ & $\mathrm{H}$ & $\mathrm{H}$ & $\mathrm{H}$ & $\mathrm{H}$ & $\mathrm{OH}$ & $\mathrm{CH}_{3}$ \\
\hline
\end{tabular}

FIGURE 2: Numbering system used to designate atom of the anthraquinone system of the molecular library examined.

analyzed. Figures 3 and 4 better highlight the fact that such contribution is proportional to the number of hydrogen bonds formed. Figure 3 also exhibits the fact that the substitution of the hydrogen atom of the hydroxyl group connected to $\mathbf{C}_{4}$ atom of the anthraquinone cycle of $\left(\mathbf{F}_{0}\right)$ by an aliphatic substituent $\left(\mathrm{E}_{0}\right)$ influences sensitively the $\mathbf{O}_{6}-\mathbf{H}$ bond distance. The induced impact of this substitution on the antioxidant power has been developed elsewhere. The diminution of large gaps observed between the $\mathbf{O}_{10}-\mathbf{H}$ and $\mathbf{O}_{6}-\mathbf{H}$ bond distances for configurations without hydrogen bond $\left(\mathrm{F}_{0}\right.$, $\mathbf{E}_{0}$, and $\mathbf{D}_{0}$ ) in gas phase is noticeable when passing from Figures 3 and 4 . This clearly enlightens the influence of the solvation on the hydrogen atom transfer (HAT).

Topological parameters of $\mathbf{O}_{6}-\mathbf{H} \ldots \mathbf{O}_{2}$ and $\mathbf{O}_{10}-\mathbf{H} \ldots \mathbf{O}_{2}$ hydrogen bonds are presented in Table 2. Collectively, we conclude that these two hydrogen bond interactions are partially covalent due to the fact that $0.5<-\mathrm{G}(\mathrm{r}) / \mathrm{v}(\mathrm{r})<1$. A close introspection of our results indicates that the electron density values for $\mathbf{O}_{6}-\mathbf{H}$. . . $\mathbf{O}_{2}$ hydrogen bond interaction are larger than that of $\mathbf{O}_{10}-\mathbf{H} \ldots \mathbf{O}_{2}$ homologues. This gives the information that the former ones are stronger than the later.
This may be related to the fact that $\mathbf{O}_{6}-\mathbf{H} \ldots \mathbf{O}_{2}$ hydrogen bond interaction is close to substitution site. The contrary observation obtained for $\mathbf{F}_{2}$ may be related to the slight weight of the methyl substituent. This enlightens the fact that the chain effect of the substituent has a sensitive influence on the nature of hydrogen bond interactions. For $\mathbf{J}_{2}$ and $\mathbf{L}_{2}$, the dissimilar facts obtained are due to the hydrogen bond located at two opposite of anthraquinone ring around each $\mathrm{C}=\mathrm{O}$ ketone group. Such localizations are obviously different from consecutive localization observed for other compounds of our molecular library.

3.2. Stability and Reactivity. The total energies, relative energies, and dipole moment calculated at B3LYP/6$311++G(d, p)$ level in gas phase and water are presented in Table 3. From this table, the influence of the conformation preferences of each compound in these media is visible. In general, the geometry preferences are dominated by the number of hydrogen bond formed. For each case, the preferential configuration is bearing the two hydrogen 
TABLE 1: Geometrical parameters useful to characterize hydrogen bonds (bond distances $(\AA)$ and bond angles $\left({ }^{\circ}\right)$ ) of various configurations adopted at B3LYP/6-311++G(d,p) in vacuum.

\begin{tabular}{|c|c|c|c|c|c|c|c|c|c|}
\hline Structures & $\begin{array}{c}\mathbf{O}_{6}-\mathbf{H}_{\ldots} \ldots \mathbf{O}_{2} \\
(\AA)\end{array}$ & $\begin{array}{c}\mathbf{O}_{6}-\mathbf{H} \\
(\AA) \\
\end{array}$ & $\begin{array}{c}\mathbf{O}_{6}-\mathrm{H} \ldots \mathbf{O}_{2} \\
\left({ }^{\circ}\right)\end{array}$ & $\begin{array}{c}\mathbf{O}_{10}-\mathbf{H} \ldots \mathbf{O}_{2} \\
(\AA)\end{array}$ & $\begin{array}{c}\mathbf{O}_{10^{-}} \mathbf{H} \\
(\AA) \\
\end{array}$ & $\begin{array}{c}\mathbf{O}_{10}-\mathbf{H} \ldots \mathbf{O}_{2} \\
\left({ }^{\circ}\right)\end{array}$ & $\begin{array}{c}\mathbf{O}_{13}-\mathbf{H} \ldots \mathbf{O}_{1} \\
(\AA)\end{array}$ & $\begin{array}{c}\mathbf{O}_{13}-\mathbf{H} \\
(\AA) \\
\end{array}$ & $\begin{array}{c}\mathbf{O}_{13}-\mathrm{H}_{\ldots} \ldots \mathbf{O}_{1} \\
\left({ }^{\circ}\right)\end{array}$ \\
\hline $\mathbf{B}_{1}$ & 1.589 & 1.00279 & 150.8 & - & - & - & - & - & - \\
\hline $\mathrm{C}_{0}$ & - & 0.97336 & & - & 0.96702 & - & - & - & - \\
\hline $\mathrm{C}_{1}$ & 1.618 & 0.99867 & 148.9 & - & 0.96750 & - & - & - & - \\
\hline $\mathrm{C}_{2}$ & 1.668 & 0.99091 & 147.3 & 1.687 & 0.98946 & 146.4 & - & - & - \\
\hline $\mathbf{D}_{0}$ & - & 0.96542 & & & 0.96708 & & - & - & - \\
\hline $\mathbf{D}_{2}$ & 1.646 & 0.99420 & 148.6 & 1.681 & 0.99025 & 146.7 & - & - & - \\
\hline $\mathbf{D}_{11}$ & 1.594 & 1.00318 & 150.3 & - & 0.96741 & & - & - & - \\
\hline $\mathbf{E}_{0}$ & - & 0.96705 & - & - & 0.96730 & & - & - & - \\
\hline $\mathrm{E}_{2}$ & 1.675 & 0.99251 & 147.4 & 1.684 & 0.99091 & 147.0 & - & - & - \\
\hline $\mathbf{F}_{0}$ & - & 0.96744 & & & 0.96743 & & - & - & - \\
\hline $\mathbf{F}_{2}$ & 1.676 & 0.99237 & 147.2 & 1.689 & 0.99030 & 146.7 & - & - & - \\
\hline $\mathbf{F}_{11}$ & - & 0.96721 & - & 1.635 & 0.99795 & 148.4 & - & - & - \\
\hline $\mathbf{G}_{0}$ & - & 0.97320 & - & - & 0.96704 & & - & - & - \\
\hline $\mathbf{G}_{1}$ & - & & - & 1.630 & 0.99827 & 148.5 & - & - & - \\
\hline $\mathbf{G}_{2}$ & 1.675 & 0.99251 & 147.4 & 1.684 & 0.99091 & 147.0 & - & - & - \\
\hline $\mathbf{G}_{11}$ & 1.615 & 0.99931 & 149.1 & - & 0.96747 & & - & - & - \\
\hline $\mathbf{H}_{1}$ & - & - & - & 1.673 & 0.99357 & 147.4 & - & - & - \\
\hline $\mathbf{J}_{0}$ & - & - & - & - & 0.96716 & & & 0.96716 & - \\
\hline $\mathrm{J}_{1}$ & - & - & - & 1.625 & 0.99757 & 148.0 & & 0.96712 & - \\
\hline $\mathbf{J}_{2}$ & - & - & - & 1.686 & 0.99619 & 146.5 & 1.687 & 0.99589 & 146.4 \\
\hline $\mathbf{J}_{11}$ & - & - & - & - & 0.96712 & & & & \\
\hline $\mathbf{K}_{0}$ & - & - & - & - & - & - & - & - & - \\
\hline $\mathbf{L}_{0}$ & - & - & - & - & 0.96717 & - & - & 0.96718 & - \\
\hline $\mathbf{L}_{1}$ & - & - & - & 1.628 & 0.99687 & 147.8 & - & 0.96716 & - \\
\hline $\mathbf{L}_{2}$ & - & - & - & 1.662 & 0.99588 & 147.4 & 1.662 & 0.99591 & 147.4 \\
\hline $\mathbf{L}_{11}$ & - & - & - & - & - & & 1.628 & 0.99713 & 147.8 \\
\hline $\mathbf{M}_{0}$ & - & 0.96689 & - & - & - & - & - & - & - \\
\hline $\mathbf{M}_{1}$ & 1.631 & 0.99803 & 148.6 & - & - & - & - & - & - \\
\hline $\mathbf{N}_{0}$ & & 0.96703 & & - & - & - & - & - & - \\
\hline $\mathbf{N}_{1}$ & 1.625 & 0.99928 & 148.8 & - & - & - & - & - & - \\
\hline $\mathbf{O}_{1}$ & 1.630 & 0.99881 & 148.6 & - & - & - & - & - & - \\
\hline $\mathbf{P}_{0}$ & - & 0.96739 & - & - & - & - & - & - & - \\
\hline $\mathbf{Q}_{0}$ & - & - & - & & 0.96716 & & - & - & - \\
\hline $\mathbf{Q}_{1}$ & - & - & - & 1.627 & 0.99907 & 148.8 & - & - & - \\
\hline $\mathbf{R}_{0}$ & & 0.96729 & & - & - & - & - & - & - \\
\hline $\mathbf{R}_{2}$ & 1.645 & 0.99497 & 147.8 & - & - & - & - & - & - \\
\hline
\end{tabular}

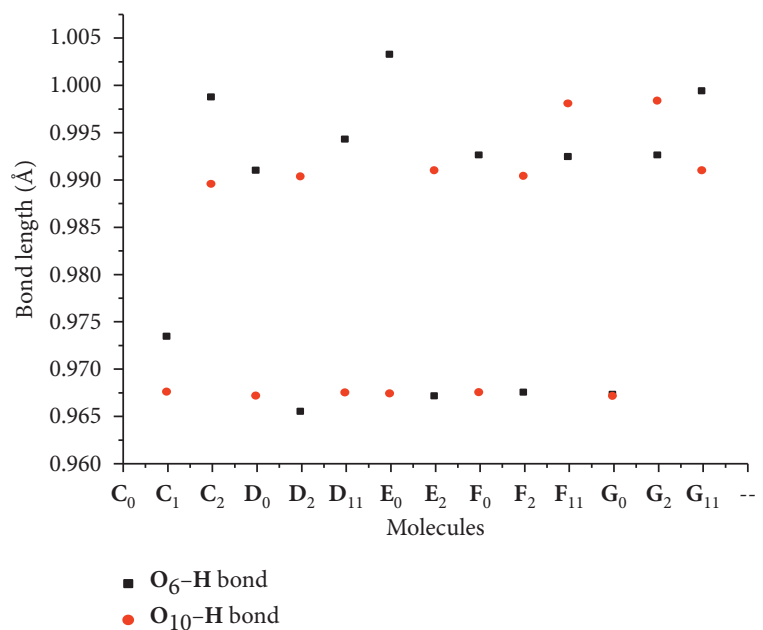

Figure 3: Graphical comparison between $\mathbf{O}_{6}-\mathbf{H}$ and $\mathbf{O}_{10}-\mathbf{H}$ bond distances at B3LYP/6-311++G(d,p) level in gas phase.

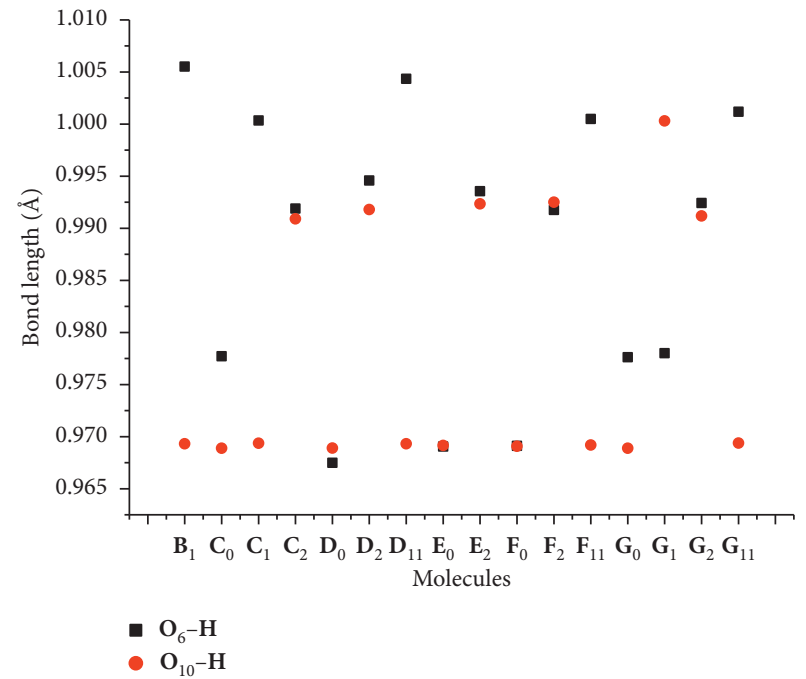

FIgURE 4: Graphical comparison between $\mathbf{O}_{6}-\mathbf{H}$ and $\mathbf{O}_{10}-\mathbf{H}$ bond distances at B3LYP/6-311++G(d,p) level in water. 
TABLE 2: Bond critical point parameters of intermolecular hydrogen bonds: electron density, Laplacian of the electron density, and hydrogen bond strength $(\mathrm{kJ} / \mathrm{mol})$ (calculated from B3LYP/6-311++G(d,p) wave function in gas phase) for anthraquinone and its derivatives.

\begin{tabular}{|c|c|c|c|c|c|c|c|}
\hline \multirow{2}{*}{ Species } & \multicolumn{7}{|c|}{$\mathrm{BCP}$ parameters } \\
\hline & $\rho(r)(\mathrm{au})$ & $\nabla^{2} \rho(r)(\mathrm{au})$ & $H_{\mathrm{BCP}}(r)(\mathrm{kJ} / \mathrm{mol})$ & $G_{\mathrm{BCP}}(r)(\mathrm{kJ} / \mathrm{mol})$ & $V_{\mathrm{BCP}}(\mathrm{kJ} / \mathrm{mol})$ & $-\left(G_{\mathrm{BCP}}(r) / V_{\mathrm{BCP}}\right)$ & $E_{\text {int }}(\mathrm{kJ} / \mathrm{mol})$ \\
\hline \multicolumn{8}{|c|}{$\mathbf{O}_{6}-\mathrm{H} \ldots \mathrm{O}_{2}$} \\
\hline $\mathbf{B}_{2}$ & 0.0493 & 0.1483 & -3.342 & 100.662 & -104.003 & 0.96 & 52.001 \\
\hline $\mathrm{C}_{2}$ & 0.0459 & 0.1412 & -1.060 & 93.737 & -94.797 & 0.98 & 47.398 \\
\hline $\mathbf{D}_{2}$ & 0.0485 & 0.1464 & -2.793 & 98.896 & -101.690 & 0.97 & 50.845 \\
\hline $\mathbf{E}_{2}$ & 0.0450 & 0.1381 & -0.692 & 91.347 & -92.039 & 0.99 & 46.019 \\
\hline $\mathbf{F}_{2}$ & 0.0436 & 0.1347 & 0.006 & 88.417 & -88.410 & 1.00 & 44.205 \\
\hline $\mathbf{G}_{2}$ & 0.0462 & 0.1416 & -1.198 & 94.155 & -95.353 & 0.98 & 47.676 \\
\hline $\mathbf{J}_{2}$ & 0.0438 & 0.1343 & -0.2285 & 88.389 & -88.617 & 0.99 & 44.308 \\
\hline $\mathbf{L}_{2}$ & 0.0466 & 0.1417 & -1.604 & 94.631 & -96.236 & 0.98 & 48.118 \\
\hline \multicolumn{8}{|c|}{$\mathbf{O}_{10}-\mathbf{H} \ldots \mathbf{O}_{2}$} \\
\hline $\mathbf{B}_{2}$ & 0.0437 & 0.1354 & 0.0223 & 88.841 & -88.819 & 1.00 & 44.409 \\
\hline $\mathrm{C}_{2}$ & 0.0437 & 0.1357 & 0.004 & 89.048 & -89.043 & 1.00 & 44.521 \\
\hline $\mathbf{D}_{2}$ & 0.0444 & 0.1374 & -0.2651 & 90.438 & -90.703 & 0.99 & 45.351 \\
\hline $\mathbf{E}_{2}$ & 0.0441 & 0.1360 & -0.2090 & 89.449 & -89.658 & 0.99 & 44.829 \\
\hline $\mathbf{F}_{2}$ & 0.0449 & 0.138 & -0.6448 & 91.163 & -91.808 & 0.99 & 45.904 \\
\hline $\mathbf{G}_{2}$ & 0.0435 & 0.1347 & 0.0690 & 88.337 & -88.2681 & 1.00 & 44.135 \\
\hline $\mathbf{J}_{2}$ & 0.0439 & 0.1346 & -31.8172 & 88.694 & -89.0122 & 0.99 & 44.506 \\
\hline $\mathbf{L}_{2}$ & 0.0466 & 0.1417 & -1.611 & 94.648 & -96.2600 & 0.98 & 48.130 \\
\hline
\end{tabular}

bonds already mentioned $\left(\mathbf{O}_{6}-\mathbf{H} \ldots \mathbf{O}_{2}\right.$ and $\mathbf{O}_{10}-\mathbf{H} \ldots \mathbf{O}_{2}$ hydrogen bonds). For instance, the configurations $\mathbf{C}_{2}, \mathbf{D}_{2}$, $\mathbf{E}_{2}$, and $\mathbf{G}_{2}$ have been recorded as preferential configuration for C, D, E, and G, respectively. It is also noticeable that the configurations with the unique $\mathbf{O}_{6}-\mathbf{H}$. . $\mathbf{O}_{2}$ hydrogen bond are more stable than their homologues with $\mathbf{O}_{10}-\mathbf{H} . \mathbf{O}_{2}$ hydrogen bond. The difference in total energy between $\mathbf{X}_{11}$ structure and $\mathbf{X}_{1}$ one is equal to 0.129 and $0.055 \mathrm{eV}$, respectively, for $\mathrm{D}$ and $\mathrm{G}$ compounds in gas phase. The drop in total energy is observed when passing to gas phase to water. The average difference is equal to $1.615 \mathrm{eV}$. A sensitive increase of dipole moment is also observed when passing to gas phase and water due to greater dielectric constant of this latter $(\varepsilon=78.4)$.

This discloses the influence of the solvent's polarity on the weakening of the $\mathbf{O}_{6}-\mathbf{H}$ and $\mathbf{O}_{10}-\mathbf{H}$ bond strength and therefore on an augmentation of antioxidant power. Although B3LYP is not parameterized for HOMO and LUMO eigenvalues, the examination of the concept of stability from a kinetic point of view is done using the HOMO-LUMO energy gap as descriptor. This quantity that is always positive can also be written as the difference between I and A. It is important to mention that high kinetic stability is related to low reactivity and large HOMO-LUMO energy gap. The HOMO-LUMO gap values range from 2.880 to $3.788 \mathrm{eV}$ (Table 3 ). The highest value is obtained for $\mathbf{G}_{0}$ configuration. The difference in this band gap between $\mathbf{G}_{0}$ configuration and the configuration of $\mathrm{G}$ with one hydrogen bond $\left(\mathbf{G}_{1}\right.$ or $\mathbf{G}_{11}$ ) is, respectively, equal to 0.347 and $0.490 \mathrm{eV}$. In the case of the formation of two hydrogen bonds $\left(\mathbf{G}_{2}\right)$, this gap difference becomes equal to $0.06 \mathrm{eV}$. These facts in good agreement with other procedures using thermodynamic constraint to examine the stability demonstrate that the preferential configuration adopted is also influenced by their orientation. The lowest value of this band gap $(2.880 \mathrm{eV})$ is yielded for conformation $\mathbf{B}_{1}$ elected to be the least stable of the molecular library adopted. This may result from the fact that the orientation of the hydrogen bond formed $\left(\mathbf{O}_{10^{-}}\right.$ $\mathbf{H} . \mathrm{O}_{2}$ ) intensifies the electrostatic repulsion between the electron doublet of $\mathbf{O}_{6}$ oxygen atom and the $\mathrm{C}=\mathrm{C}$ double bond (of the $R_{7}$ substituent) closer to this latter. The diminution of the band gap values observed in water (Table 3 ) displays the strong solute-solvent interaction that diminishes the stability. The global reactivity descriptors (GRDs; electrophilicity index $(\omega)$; electronegativity $(\chi)$, global softness $(S)$, and global hardness $(\eta)$ ) calculated for each anthraquinone derivative of our molecular library are shown in Table 4 . The latter descriptor is related to measurement of the resistance to electron cloud polarization provoked by small perturbation from chemical reactions [20]. The highest $\eta$ value in various media observed (1.864 and $1.810 \mathrm{eV}$, respectively, in gas phase and water) for $\mathbf{G}_{0}$ conformation of $\mathrm{G}$ (Table 4 ) indicates that this configuration is kinetically the most stable. For the examined structures, $\mathbf{G}_{2}, \mathbf{O}_{0}$, and $\mathbf{C}_{2}$ are shown as the most reactive molecular system due to their relatively low hardness value of 0.394 , 1.238 , and $1.591 \mathrm{eV}$, respectively. Furthermore, the global electrophilicity that characterizes the capacity of a system to gain an electron is an additive parameter to predict the chemical reactivity of compound. It also gives an indication on the deterioration of the binding energy due to a maximum electron flow between a donor and an acceptor [24]. In terms of electrophilicity, the most reactive compound is found to be $\mathbf{G}_{1}(6.803 \mathrm{eV})$, whereas the lowest value matches up with $\mathrm{B}_{\mathrm{O}}(6.131 \mathrm{eV})$ in gas phase. In water, a minor augmentation of molecular $\chi$ indices is observed compared to that calculated in gas phase, while a diminution of $\eta$ indices is observed. This influence of the solvent on hardness values of neutral molecules has been previously computed by De Proft and Geerlings [25]. Additionally, Parr et al. 
TABLE 3: Total energy (in hartree), relative total energy ( $\mathrm{kJ} / \mathrm{mol})$, HOMO-LUMO gap (eV), and dipole moment (in debye) calculated at B3LYP/6-311++G(d,p) level in vacuum and water.

\begin{tabular}{|c|c|c|c|c|c|}
\hline \multicolumn{2}{|c|}{ Molecule } & $E_{\mathrm{T}}$ (hartree) & $\Delta E_{\mathrm{T}}(\mathrm{kJ} / \mathrm{mol})$ & HOMO-LUMO gap (eV) & $\mu$ (debye) \\
\hline \multicolumn{6}{|c|}{ Gas } \\
\hline \multirow{2}{*}{ A } & $\mathbf{A}_{1}$ & -991.88935236 & -31.0 & 3.532 & 5.3749 \\
\hline & $\mathbf{A}_{11}$ & -991.90114294 & 00.0 & 3.254 & 3.8716 \\
\hline \multirow{2}{*}{ B } & $\mathbf{B}_{0}$ & -1188.46341037 & -59.6 & 3.238 & 2.2851 \\
\hline & $\mathbf{B}_{1}$ & -1188.48612006 & 00.0 & 2.880 & 3.4110 \\
\hline & $\mathrm{C}_{0}$ & -1034.61079019 & -107.3 & 3.713 & 3.2223 \\
\hline \multirow[t]{4}{*}{$\mathrm{C}$} & $\mathrm{C}_{1}$ & -1034.63184633 & -52.0 & 3.255 & 2.3548 \\
\hline & $\mathrm{C}_{2}$ & -1034.65163987 & 00.0 & 3.181 & 1.1488 \\
\hline & $\mathbf{D}_{0}$ & -1305.18903053 & -130.0 & 3.680 & 3.9481 \\
\hline & $\mathbf{D}_{2}$ & -1305.23841440 & 00.0 & 3.331 & 3.5783 \\
\hline \multirow{2}{*}{ D } & $\mathbf{D}_{1}$ & -1305.21788653 & -53.9 & 3.371 & 1.1877 \\
\hline & $\mathbf{D}_{11}$ & -1305.21313812 & -66.4 & 3.444 & 7.2155 \\
\hline \multirow{2}{*}{$\mathbf{E}$} & $\mathbf{E}_{0}$ & -1344.49863299 & -121.9 & 3.644 & 2.3848 \\
\hline & $\mathbf{E}_{2}$ & -1344.54506498 & 00.0 & 3.320 & 2.8021 \\
\hline \multirow{2}{*}{$\mathbf{F}$} & $\mathbf{F}_{0}$ & -953.84162893 & 00.0 & 3.342 & 0.4286 \\
\hline & $\mathbf{F}_{1}$ & -953.81966537 & -57.7 & 3.412 & 3.6543 \\
\hline \multirow{4}{*}{ G } & $\mathbf{G}_{0}$ & -1073.93265173 & -109.1 & 3.788 & 2.7529 \\
\hline & $\mathbf{G}_{1}$ & -1073.95621582 & -47.2 & 3.441 & 4.4560 \\
\hline & $\mathbf{G}_{11}$ & -1073.95421286 & -52.5 & 3.298 & 3.0876 \\
\hline & $\mathbf{G}_{2}$ & -1073.97421089 & 00.0 & 3.728 & 0.8737 \\
\hline \multirow{4}{*}{$\mathbf{J}$} & $\mathbf{J}_{0}$ & - & - & - & - \\
\hline & $\mathbf{J}_{1}$ & - & - & - & - \\
\hline & $\mathbf{J}_{11}$ & - & - & - & - \\
\hline & $\mathbf{J}_{2}$ & - & - & - & - \\
\hline & $\mathbf{L}_{0}$ & - & - & - & - \\
\hline \multirow{3}{*}{$\mathbf{L}$} & $\mathbf{L}_{1}$ & - & - & - & - \\
\hline & $\mathbf{L}_{11}$ & - & - & - & - \\
\hline & $\mathbf{L}_{2}$ & - & - & - & - \\
\hline \multirow{2}{*}{$\mathrm{H}$} & $\mathbf{H}_{0}$ & -1031.22294791 & -106.5 & 3.456 & 1.9298 \\
\hline & $\mathbf{H}_{1}$ & -1031.26351886 & 00.0 & 3.470 & 2.9134 \\
\hline \multirow{2}{*}{ M } & $\mathbf{M}_{0}$ & -1068.32636054 & -61.8 & 3.574 & 4.5573 \\
\hline & $\mathbf{M}_{1}$ & -1068.34988875 & 00.0 & 3.368 & 1.2673 \\
\hline \multirow{2}{*}{$\mathbf{N}$} & $\mathbf{N}_{0}$ & -1146.93000528 & -64.8 & 3.230 & 2.5595 \\
\hline & $\mathbf{N}_{1}$ & -1146.95467181 & 00.0 & 3.568 & 1.9543 \\
\hline \multirow{2}{*}{$\mathrm{O}$} & $\mathbf{O}_{0}$ & -953.80221624 & -65.6 & 2.476 & 3.1499 \\
\hline & $\mathbf{O}_{1}$ & -953.82718872 & 00.0 & 3.429 & 0.3614 \\
\hline \multirow[t]{2}{*}{$\mathbf{P}$} & $\mathbf{P}_{0}$ & -1032.41067816 & 00.0 & 3.664 & 0.4174 \\
\hline & $\mathbf{R}_{0}$ & -1220.97875578 & -55.8 & 3.569 & 8.2723 \\
\hline \multirow[t]{2}{*}{$\mathbf{R}$} & $\mathbf{R}_{1}$ & -1220.99999638 & 00.0 & 3.330 & 7.3222 \\
\hline & $\mathbf{R}_{11}$ & -1220.97391698 & -68.5 & 3.657 & 1.9344 \\
\hline \multicolumn{6}{|c|}{ Water } \\
\hline 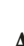 & $\mathbf{A}_{1}$ & -991.91461473 & 0.000 & 3.391 & 5.3175 \\
\hline A & $\mathbf{A}_{11}$ & -991.90856605 & -15.9 & 3.229 & 7.5989 \\
\hline B & $\mathbf{B}_{0}$ & -1188.50360416 & 00.0 & - & 4.9029 \\
\hline I & $\mathbf{B}_{1}$ & -1034.63295965 & -74.2 & 2.903 & 4.2729 \\
\hline & $\mathrm{C}_{0}$ & -1034.64768385 & -35.5 & 3.604 & 3.2799 \\
\hline $\mathrm{C}$ & $\mathrm{C}_{1}$ & -1034.66121839 & 00.0 & 3.219 & 1.4395 \\
\hline & $\mathrm{C}_{2}$ & -953.82438703 & -80.5 & 3.111 & 3.1109 \\
\hline & $\mathbf{D}_{0}$ & -953.84069182 & -37.7 & - & 5.1916 \\
\hline I & $\mathbf{D}_{2}$ & -953.85505800 & 00.0 & - & 0.6520 \\
\hline 1 & $\mathrm{D}_{1}$ & -1073.95523039 & -75.5 & - & 3.8526 \\
\hline & $\mathbf{D}_{11}$ & -1073.97127330 & -33.4 & - & 5.6682 \\
\hline $\mathrm{E}$ & $\mathbf{E}_{0}$ & -1073.97043781 & -35.6 & - & 4.2197 \\
\hline E & $\mathbf{E}_{2}$ & -1073.98399050 & 00.0 & - & 1.1556 \\
\hline F & $\mathbf{F}_{0}$ & -878.59020761 & -84.8 & 3.588 & 4.5416 \\
\hline $\mathbf{F}$ & $\mathbf{F}_{1}$ & -878.60696218 & -40.8 & 3.392 & 0.9897 \\
\hline
\end{tabular}


TABLE 3: Continued.

\begin{tabular}{|c|c|c|c|c|c|}
\hline \multicolumn{2}{|c|}{ Molecule } & $E_{\mathrm{T}}$ (hartree) & $\Delta E_{\mathrm{T}}(\mathrm{kJ} / \mathrm{mol})$ & HOMO-LUMO gap $(\mathrm{eV})$ & $\mu$ (debye) \\
\hline \multirow{4}{*}{ G } & $\mathbf{G}_{0}$ & -878.60678176 & -41.3 & 3.619 & 0.4114 \\
\hline & $\mathbf{G}_{1}$ & -878.62251765 & 00.0 & 3.419 & 3.8084 \\
\hline & $\mathbf{G}_{11}$ & -803.37934251 & - & 3.262 & 1.6147 \\
\hline & $\mathbf{G}_{2}$ & -839.26823982 & -83.8 & 3.162 & 5.4234 \\
\hline \multirow{4}{*}{$\mathbf{J}$} & $\mathbf{J}_{0}$ & 6.402 & 3.1 & 3.322 & 4.740 \\
\hline & $\mathbf{J}_{1}$ & 6.434 & 3.3 & 3.169 & 4.849 \\
\hline & $\mathbf{J}_{11}$ & 6.392 & 3.3 & 3.12 & 4.833 \\
\hline & $\mathbf{J}_{2}$ & 6.399 & 3.4 & 2.978 & 4.909 \\
\hline \multirow{4}{*}{$\mathbf{L}$} & $\mathbf{L}_{0}$ & 6.421 & 3.1 & 3.31 & 4.765 \\
\hline & $\mathrm{L}_{1}$ & 6.408 & 3.3 & 3.107 & 4.855 \\
\hline & $\mathbf{L}_{11}$ & 6.409 & 3.3 & 3.108 & 4.855 \\
\hline & $\mathbf{L}_{2}$ & 6.425 & 3.5 & 2.971 & 4.939 \\
\hline \multirow{2}{*}{$\mathbf{H}$} & $\mathbf{H}_{0}$ & -839.28468437 & -40.6 & - & 1.3825 \\
\hline & $\mathbf{H}_{1}$ & -839.28468396 & -40.6 & - & 1.3750 \\
\hline \multirow{2}{*}{$\mathbf{M}$} & $\mathbf{M}_{0}$ & -839.30015025 & 00.0 & 3.605 & 2.8141 \\
\hline & $\mathbf{M}_{1}$ & -1068.35243798 & -41.6 & 3.31 & 6.1355 \\
\hline \multirow{2}{*}{$\mathbf{N}$} & $\mathbf{N}_{0}$ & -1068.36826610 & 00.0 & 3.107 & 1.5752 \\
\hline & $\mathbf{N}_{1}$ & -1146.95130297 & -44.5 & 3.108 & 3.6464 \\
\hline \multirow{2}{*}{$\mathbf{O}$} & $\mathbf{O}_{0}$ & -1146.96826541 & 00.0 & 2.971 & 2.5834 \\
\hline & $\mathbf{O}_{1}$ & -953.84300988 & -0.3 & 3.464 & 3.6713 \\
\hline \multirow[t]{2}{*}{$\mathbf{P}$} & $\mathbf{P}_{0}$ & -953.84311564 & 00.0 & 3.294 & 0.6633 \\
\hline & $\mathbf{R}_{0}$ & -1032.42917558 & - & 3.475 & 0.6877 \\
\hline \multirow[t]{2}{*}{$\mathbf{R}$} & $\mathbf{R}_{1}$ & -993.12787572 & -45.0 & 3.304 & 4.4763 \\
\hline & $\mathbf{R}_{11}$ & -993.14500595 & 00.0 & 3.388 & 2.7371 \\
\hline
\end{tabular}

established a clear correlation between the change of global reactivity descriptor index and the solvation energy within the background of the reaction field theory [24].

3.3. Antioxidant Properties. The examination of antioxidant power of compound is done from the calculated single electron transfer enthalpies (in the environments adopted) and inserted in Table 4. Among the studied compounds, $\mathbf{B}_{0}$ configuration is displayed as the most antioxidant compounds due to its relatively lowest IP value $(5.816 \mathrm{eV})$. The extension of the conjugation of the system by the 3-methylbut-1-ene substituent at position 5 in the anthraquinone ring may be the plausible explanation. This is in good agreement with previous work on the resonance effect on scavenging capacity [26]. The $0.567 \mathrm{eV}$ augmentation in IP value resulted from the shift of the $\mathrm{C}=\mathrm{C}$ double bond far from the anthraquinone ring that provokes the decay of this external conjugation $\left(\mathbf{G}_{0}\right)$ confirms the influence on such extension on antioxidant power. In $\mathbf{G}_{0}$ conformation, the double substitution of the methoxy group close to the unsaturated substituent by a hydrogen atom in one hand and that of the methyl group connected to $\mathrm{C}_{12}$ carbon atom by hydrogen atom in other hand induces a minor $0.057 \mathrm{eV}$ increase in IP $\left(\mathbf{C}_{0}\right)$. The decrease of IPs related to a double suppression enlightens the enhancement of the antioxidant potential due to an insertion of an electron donor substituent in an organic system. This finding has already been underlined through the assessment of the radical scavenging activity of juglone and its derivatives done by Jin [27]. The $0.299 \mathrm{eV}$ drop in IP obtained after a replacement of the hydrogen atom attached to $\mathbf{C}_{5}$ carbon atom of $\mathbf{F}_{0}$ by a great aliphatic substituent $\left(\mathbf{D}_{0}\right)$ exhibits the influence of the steric hindrance on the antioxidant activity observed during the study of Schiff base ligands and their copper (II) complexes [28]. A $0.363 \mathrm{eV}$ similar decrease in IP $\left(\mathbf{E}_{0}\right)$ has been yielded by substituting the hydrogen atom of hydroxide group bound to $\mathbf{C}_{4}$ carbon atom of $\left(\mathbf{F}_{0}\right)$ by this same aliphatic substituent. A noticeable variation of IPs is observed when moving to one configuration of a compound to another. In the case of $\mathbf{D}$ structure, the gas phase IP values for $\mathbf{D}$ configurations increase in the order: $\mathbf{D}_{0}<\mathbf{D}_{1}<\mathbf{D}_{11}<\mathbf{D}_{2}$. Our B3LYP results are then in good agreement with the kinetic and thermodynamic experimental study of the influence of intramolecular hydrogen bond on the antioxidant activity of $o$-bisphenols (2,2' ${ }^{\prime}$-methylenebis(6-tertbutyl-4methylphenol), 2,2'-ethylidenebis(4,6-di-tert-butylphenol), and 4,4'-methylenebis(2,6-di-tert-butylphenol)) [29].

The comparison of the IPs calculated to those of classical phenolic acids [30] (8.218, 7.907, and $7.699 \mathrm{eV}$ yielded, respectively, for gallic acid, caffeic acid, and ferulic acid at the B3LYP/6-311++G(d,p) level) indicates that the SET mechanism is more prominent for compounds of the molecular library analyzed. The survey of the literature shows that IP values obtained for the ascorbic acid [31] at B3LYP/6$311++\mathrm{G}(2 \mathrm{~d}, 2 \mathrm{p})$ level of theory are equal to $8.331 \mathrm{eV}$ in gas phase. Despite the basis set effect, the ET mechanism is also more prominent in anthraquinone derivatives than in ascorbic acid. The IPs in water are lower than those obtained in gas phase. The average difference in IP equal to $0.114 \mathrm{eV}$ in comparison with those obtained in gas phase is attributed to the great sensibility of cation radicals to the polarity of water.

3.4. Antiradical Properties. Table 5 presents electrodonating $\left(\omega^{-}\right)$and electroaccepting $\left(\omega^{+}\right)$power and donor $\left(R_{\mathrm{d}}\right)$ and 
TABLE 4: Ionization potential (IP in eV), electron affinity (A in $\mathrm{eV}$ ), global hardness $(\eta$ in $\mathrm{eV})$, global softness $(\mathrm{S}$ in $\mathrm{eV})$, and electrophilicity index $(\omega$ in $\mathrm{eV})$ calculated at B3LYP/6-311++G(d,p) level in vacuum and water.

\begin{tabular}{|c|c|c|c|c|c|c|c|}
\hline \multicolumn{2}{|c|}{ Molecule } & $I$ & $A$ & $\eta$ & $\chi$ & $s$ & $\omega$ \\
\hline \multicolumn{8}{|c|}{ Gas } \\
\hline \multirow{2}{*}{ A } & $\mathbf{A}_{1}$ & 6.788 & 3.256 & 1.766 & 5.022 & 0.283 & 6.731 \\
\hline & $\mathbf{A}_{11}$ & 6.696 & 3.442 & 1.627 & 5.069 & 0.307 & 6.689 \\
\hline \multirow{3}{*}{ B } & $\mathbf{B}_{0}$ & 5.816 & 2.578 & 1.619 & 4.197 & 0.309 & 6.131 \\
\hline & $\mathbf{B}_{1}$ & 5.890 & 3.010 & 1.440 & 4.450 & 0.347 & 6.661 \\
\hline & $\mathrm{C}_{0}$ & 6.440 & 2.727 & 1.857 & 4.584 & 0.269 & 6.504 \\
\hline \multirow[t]{3}{*}{$\mathrm{C}$} & $\mathrm{C}_{1}$ & 6.386 & 3.131 & 1.628 & 4.759 & 0.307 & 6.544 \\
\hline & $\mathrm{C}_{2}$ & 6.576 & 3.395 & 1.591 & 4.985 & 0.314 & 6.657 \\
\hline & $\mathbf{D}_{0}$ & 6.354 & 2.674 & 1.840 & 4.514 & 0.272 & 6.612 \\
\hline \multirow{3}{*}{ D } & $\mathbf{D}_{2}$ & 6.574 & 3.243 & 1.666 & 4.909 & 0.300 & 6.663 \\
\hline & $\mathbf{D}_{1}$ & 6.382 & 3.011 & 1.685 & 4.696 & 0.297 & 6.631 \\
\hline & $\mathbf{D}_{11}$ & 6.395 & 2.951 & 1.722 & 4.673 & 0.290 & 6.628 \\
\hline \multirow{3}{*}{ E } & $\mathrm{E}_{0}$ & 6.290 & 2.646 & 1.822 & 4.468 & 0.274 & 6.490 \\
\hline & $\mathbf{E}_{2}$ & 6.470 & 3.150 & 1.660 & 4.810 & 0.301 & 6.533 \\
\hline & $\mathbf{F}_{0}$ & 6.653 & 3.311 & 1.671 & 4.982 & 0.299 & 6.402 \\
\hline \multirow[t]{3}{*}{$\mathbf{F}$} & $\mathbf{F}_{1}$ & 6.465 & 3.053 & 1.706 & 4.759 & 0.293 & 6.434 \\
\hline & $\mathbf{F}_{2}$ & - & - & - & - & - & - \\
\hline & $\mathbf{G}_{0}$ & 6.383 & 2.655 & 1.864 & 4.519 & 0.268 & 6.392 \\
\hline \multirow{3}{*}{ G } & $\mathbf{G}_{1}$ & 6.388 & 2.947 & 1.720 & 4.667 & 0.290 & 6.399 \\
\hline & $\mathbf{G}_{11}$ & 6.335 & 3.037 & 1.649 & 4.686 & 0.303 & 6.803 \\
\hline & $\mathbf{G}_{2}$ & 6.527 & 5.739 & 0.394 & 6.133 & 1.268 & 6.421 \\
\hline \multirow{3}{*}{$\mathbf{H}$} & $\mathbf{H}_{0}$ & 6.350 & 2.894 & 1.728 & 4.622 & 0.289 & 6.408 \\
\hline & $\mathbf{H}_{1}$ & 6.791 & 3.321 & 1.735 & 5.056 & 0.288 & 6.409 \\
\hline & $\mathbf{J}_{0}$ & - & - & - & - & - & - \\
\hline \multirow{3}{*}{$\mathbf{J}$} & $\mathbf{J}_{1}$ & - & - & - & - & - & - \\
\hline & $\mathbf{J}_{11}$ & - & - & - & - & - & - \\
\hline & $\mathbf{J}_{2}$ & - & - & - & - & - & - \\
\hline \multirow[t]{2}{*}{$\mathbf{K}$} & $\mathbf{K}_{0}$ & - & - & - & - & - & - \\
\hline & $\mathbf{L}_{0}$ & - & - & - & - & - & - \\
\hline \multirow{3}{*}{$\mathbf{L}$} & $\mathbf{L}_{1}$ & - & - & - & - & - & - \\
\hline & $\mathbf{L}_{11}$ & - & - & - & - & - & - \\
\hline & $\mathbf{L}_{2}$ & - & - & - & - & - & - \\
\hline \multirow{2}{*}{$\mathbf{M}$} & $\mathbf{M}_{0}$ & 6.293 & 2.719 & 1.787 & 4.506 & 0.280 & 6.425 \\
\hline & $\mathbf{M}_{1}$ & 6.397 & 3.029 & 1.684 & 3.029 & 0.297 & 6.417 \\
\hline \multirow{2}{*}{$\mathbf{N}$} & $\mathbf{N}_{0}$ & 6.329 & 0.099 & 1.819 & 4.511 & 0.275 & 6.455 \\
\hline & $\mathbf{N}_{1}$ & 6.364 & 2.976 & 1.694 & 4.670 & 0.295 & 6.468 \\
\hline \multirow{2}{*}{ O } & $\mathbf{O}_{0}$ & 6.489 & 4.013 & 1.238 & 5.251 & 0.404 & 6.487 \\
\hline & $\mathbf{O}_{1}$ & 6.607 & 3.178 & 1.714 & 4.892 & 0.292 & 6.620 \\
\hline $\mathbf{P}$ & $\mathbf{P}_{0}$ & 6.431 & 2.767 & 1.832 & 4.599 & 0.273 & 6.625 \\
\hline O & $\mathbf{Q}_{0}$ & - & - & - & - & - & - \\
\hline$Q$ & $\mathbf{Q}_{1}$ & - & - & - & - & - & - \\
\hline & $\mathbf{R}_{0}$ & 6.745 & 3.176 & 1.784 & 4.961 & 0.280 & 6.547 \\
\hline $\mathbf{R}$ & $\mathbf{R}_{1}$ & 6.776 & 3.446 & 1.665 & 5.111 & 0.300 & 6.536 \\
\hline & $\mathbf{R}_{1}$ & 6.600 & 2.943 & 1.828 & 4.772 & 0.273 & 6.541 \\
\hline$S$ & $\mathrm{~S}_{0}$ & - & - & - & - & - & - \\
\hline & & & & & & & \\
\hline A & $\mathbf{A}_{1}$ & 6.731 & 3.340 & 1.695 & 5.034 & 0.295 & 0.275 \\
\hline A & $\mathbf{A}_{11}$ & 6.689 & 3.460 & 1.614 & 5.075 & 0.310 & 0.293 \\
\hline B & $\mathbf{B}_{0}$ & - & - & - & - & - & - \\
\hline B & $\mathbf{B}_{1}$ & 6.131 & 3.228 & 1.453 & 4.680 & 0.344 & 0.277 \\
\hline & $\mathrm{C}_{0}$ & 6.661 & 3.057 & 1.801 & 4.860 & 0.277 & 0.241 \\
\hline C & $\mathrm{C}_{1}$ & 6.504 & 3.285 & 1.608 & 4.895 & 0.311 & 0.271 \\
\hline & $\mathrm{C}_{2}$ & 6.544 & 3.433 & 1.556 & 4.988 & 0.321 & 0.294 \\
\hline & $\mathbf{D}_{0}$ & - & - & - & - & - & - \\
\hline D & $\mathbf{D}_{2}$ & - & - & - & - & - & - \\
\hline $\mathbf{D}$ & $\mathbf{D}_{1}$ & - & - & - & - & - & - \\
\hline & $\mathrm{D}_{11}$ & - & - & - & - & - & - \\
\hline
\end{tabular}

TABLE 4: Continued.

\begin{tabular}{|c|c|c|c|c|c|c|c|}
\hline \multicolumn{2}{|c|}{ Molecule } & \multirow{2}{*}{$\frac{I}{-}$} & \multirow{2}{*}{$\begin{array}{l}A \\
-\end{array}$} & \multirow{2}{*}{$\eta$} & \multirow{2}{*}{$\frac{\chi}{-}$} & \multirow{2}{*}{$\frac{s}{-}$} & \multirow{2}{*}{$\omega$} \\
\hline F & $\mathbf{E}_{0}$ & & & & & & \\
\hline $\mathbf{E}$ & $\mathbf{E}_{2}$ & - & - & - & - & - & - \\
\hline \multirow{4}{*}{$\mathbf{F}$} & $\mathbf{F}_{0}$ & 6.657 & 3.069 & 1.793 & 4.863 & 0.279 & 0.242 \\
\hline & $\mathrm{F}_{1}$ & 6.612 & 3.220 & 1.695 & 4.917 & 0.295 & 0.262 \\
\hline & $\mathbf{F}_{2}$ & 6.663 & 3.358 & 1.652 & 5.010 & 0.303 & 0.279 \\
\hline & $\mathbf{G}_{0}$ & 6.631 & 3.012 & 1.810 & 4.822 & 0.276 & 0.236 \\
\hline \multirow{3}{*}{ G } & $\mathbf{G}_{1}$ & 6.628 & 3.209 & 1.709 & 4.920 & 0.292 & 0.260 \\
\hline & $\mathbf{G}_{11}$ & 6.490 & 3.228 & 1.630 & 4.860 & 0.307 & 0.266 \\
\hline & $\mathbf{G}_{2}$ & 6.533 & 3.371 & 1.581 & 4.952 & 0.316 & 0.285 \\
\hline \multirow{3}{*}{ H } & $\mathbf{H}_{0}$ & - & - & - & - & - & - \\
\hline & $\mathbf{H}_{1}$ & - & - & - & - & - & - \\
\hline & $\mathbf{J}_{0}$ & 6.402 & 3.080 & 1.660 & 4.740 & 0.301 & 0.249 \\
\hline \multirow{3}{*}{ J } & $\mathbf{J}_{1}$ & 6.434 & 3.265 & 1.584 & 4.849 & 0.316 & 0.273 \\
\hline & $\mathbf{J}_{11}$ & 6.392 & 3.272 & 1.559 & 4.833 & 0.321 & 0.275 \\
\hline & $\mathbf{J}_{2}$ & 6.399 & 3.421 & 1.48 & 4.90 & 0.3 & 0.297 \\
\hline \multirow[t]{2}{*}{ K } & $\mathbf{K}_{0}$ & 6.803 & 3.198 & 1.801 & 5.001 & 0.277 & 0.2545 \\
\hline & $\mathbf{L}_{0}$ & 6.421 & 3.111 & 1.654 & 4.765 & 0.302 & 0.252 \\
\hline \multirow{3}{*}{$\mathbf{L}$} & $\mathbf{L}_{1}$ & 6.408 & 3.301 & 1.554 & 4.855 & 0.322 & 0.279 \\
\hline & $\mathbf{L}_{11}$ & 6.409 & 3.301 & 1.554 & 4.855 & 0.322 & 0.279 \\
\hline & $\mathbf{L}_{2}$ & 6.425 & 3.454 & 1.486 & 4.939 & 0.337 & 0.302 \\
\hline \multirow{2}{*}{ M } & $\mathbf{M}_{0}$ & 6.417 & 2.953 & 1.733 & 4.686 & 0.289 & 0.233 \\
\hline & $\mathbf{M}_{1}$ & 6.455 & 3.161 & 1.646 & 4.808 & 0.304 & 0.258 \\
\hline \multirow{2}{*}{$\mathbf{N}$} & $\mathbf{N}_{0}$ & 6.468 & 2.993 & 1.739 & 4.729 & 0.288 & 0.236 \\
\hline & $\mathbf{N}_{1}$ & 6.487 & 3.183 & 1.652 & 4.835 & 0.303 & 0.260 \\
\hline \multirow{2}{*}{ O } & $\mathbf{O}_{0}$ & 6.620 & 3.232 & 1.695 & 4.925 & 0.295 & 0.263 \\
\hline & $\mathbf{O}_{1}$ & 6.625 & 3.247 & 1.690 & 4.936 & 0.296 & 0.265 \\
\hline $\mathbf{P}$ & $\mathbf{P}_{0}$ & 6.547 & 3.043 & 1.752 & 4.795 & 0.285 & 0.241 \\
\hline \multirow{3}{*}{$\mathbf{Q}$} & $\mathbf{Q}_{0}$ & 6.536 & 3.020 & 1.758 & 4.778 & 0.284 & 0.239 \\
\hline & $\mathbf{Q}_{1}$ & 6.541 & 3.195 & 1.674 & 4.868 & 0.299 & 0.260 \\
\hline & $\mathbf{R}_{0}$ & - & - & - & - & - & - \\
\hline \multirow[t]{2}{*}{$\mathbf{R}$} & $\mathbf{R}_{1}$ & 6.729 & 3.427 & 1.652 & 5.078 & 0.303 & 0.287 \\
\hline & $\mathbf{R}_{1}$ & 6.687 & 3.257 & 1.714 & 4.972 & 0.292 & 0.265 \\
\hline$S$ & $\mathrm{~S}_{0}$ & 6.527 & 3.079 & 1.725 & 4.803 & 0.290 & 0.246 \\
\hline
\end{tabular}

acceptor $\left(R_{\mathrm{a}}\right)$ index. The values of electron affinity calculated for anthraquinone derivatives are significantly greater than those of vitamin $\mathrm{C}(1.062 \mathrm{eV})$ and gallic acid $(1.578 \mathrm{eV})$ with exception of $\mathbf{N}_{0}(0.099 \mathrm{eV})$. This indicates that this latter one is the unique good electroacceptor in gas phase. But all the compounds studied have shown to be bad electron acceptor in water. It is noteworthy that lower electrodonating power $\left(\omega^{-}\right)$means good capacity to donate an electron, whereas higher electroaccepting power $\left(\omega^{+}\right)$denotes good capacity to accept an electron. On Figures 5 and 6, donor-acceptor map (DAM) for $R_{\mathrm{d}}$ and $R_{\mathrm{a}}$ values of examined compounds are, respectively, shown for gas phase and water. It is shown that $R_{\mathrm{d}}>1$ in gas phase demonstrating that all the compounds studied are poorer donors than $\mathrm{Na}$. This fact is observed in aqueous solution only for six of them $\left(\mathbf{A}_{11}, \mathbf{A}_{1}, \mathbf{C}_{0}, \mathbf{C}_{1}, \mathbf{C}_{2}\right.$, and $\mathbf{B}_{1}$ ). Exception made for $\mathbf{C}_{2}$, all the anthraquinone derivatives examined are poorer acceptors than (F) in gas phase due to $R_{\mathrm{a}}<1$. Similar results are yielded in water with exception for $\mathbf{J}_{1}(1.013 \mathrm{eV})$. Figure 5 illustrates higher antiradical behavior as electron donor with respect to the electron capacity of vitamin $\mathrm{C}$ in gas phase. Identical facts have been observed for gallic acid with exception for four compounds $\left(\mathbf{A}_{1}, \mathbf{H}_{1}, \mathbf{R}_{0}\right.$, and $\left.\mathbf{R}_{1}\right)$ in this environment. In water, the majority of anthraquinone derivatives have 


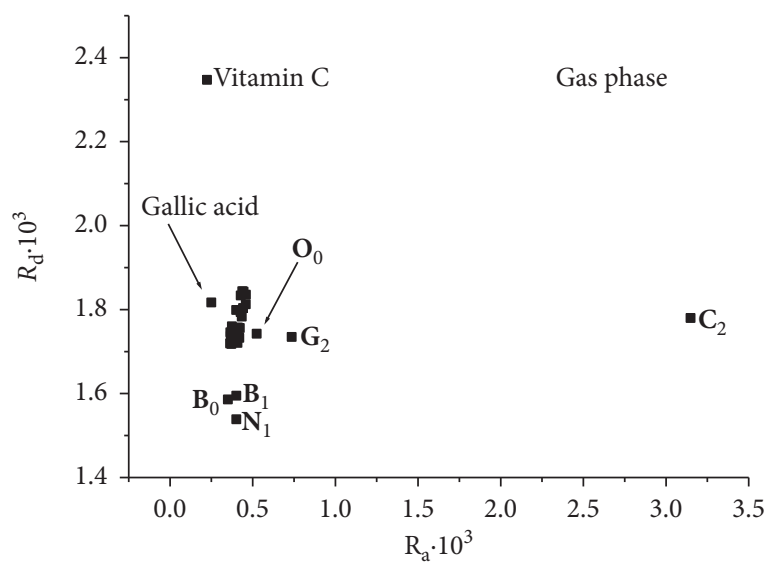

Figure 5: Donor-acceptor maps of anthraquinone derivatives, vitamin $\mathrm{C}$, and gallic acid in gas phase.

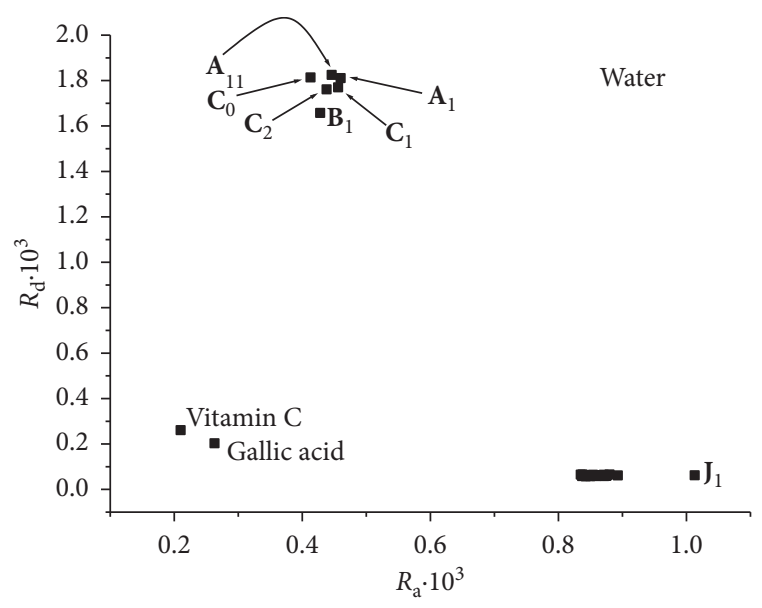

FIGURE 6: Donor-acceptor maps of anthraquinone derivatives, vitamin $\mathrm{C}$, and gallic acid in water.

displayed a better result as electron donor compared to the electron donor capacity of these two classical vitamins with exception of few of them $\left(\mathbf{A}_{11}, \mathbf{A}_{1}, \mathbf{C}_{0}, \mathbf{C}_{1}, \mathbf{C}_{2}\right.$, and $\left.\mathbf{B}_{1}\right)$. A close introspection of Table 5 shows the fact that the formation of hydrogen bonds in anthraquinone derivatives leads to a versatile effect on antiradical behavior in terms of electron donor: An insertion of hydrogen bond in the configuration $\mathbf{G}_{0}$ (1.7459) provokes a slight decrease in $R_{\mathrm{d}}$ $\left(\mathbf{G}_{1}\right.$ (1.7382), $\mathbf{G}_{11}(1.7207)$, and $\mathbf{G}_{2}$ (1.7349). A similar operation on its homologue $\mathbf{D}_{0}(1.7371)$ yields an augmentation in $R_{\mathrm{d}}\left(\mathbf{D}_{1}(1.7832)\right.$ and $\mathbf{D}_{2}(1.7401)$. The 0.1489 increase in $R_{\mathrm{d}}$ that pertains the migration of the $\mathrm{C}=\mathrm{C}$ double bond of the 3 methylbut-1-ene substituent at position 5 in the anthraquinone system of the configuration $\mathbf{B}_{0}$ toward the methyl group of this substituent $\left(\mathbf{G}_{0}\right)$ exhibits the deterioration of the antiradical activity. This is attributed to the rupture of the extension of conjugation of this system $\left(\mathbf{B}_{0}\right)$. A slight deterioration of antiradical performance is also observed when the two electron donor groups $\mathrm{CH}_{3} \mathrm{O}$ and $\mathrm{CH}_{3}$, respectively, attached to $\mathbf{C}_{4}$ and $\mathbf{C}_{12}$ carbon atoms of anthraquinone system of the configuration $\mathbf{G}_{0}$ are replaced by hydrogen
TABLE 5: Ionization potential $(\mathrm{eV})$, electron affinity $(\mathrm{eV})$, electrodonating power $\left(\omega^{-}\right)$and electroaccepting power $\left(\omega^{+}\right)$, donor index $\left(R_{\mathrm{d}}\right)$, and acceptor index $\left(R_{\mathrm{a}}\right)$ calculated at B3LYP/6$311++\mathrm{G}(\mathrm{d}, \mathrm{p})$ in vacuum and water.

\begin{tabular}{|c|c|c|c|c|c|c|c|}
\hline Molecule & & $I$ & $A$ & $\omega^{-}$ & $\omega^{+}$ & $R_{\mathrm{d}}$ & $R_{\mathrm{a}}$ \\
\hline \multicolumn{8}{|l|}{ Gas } \\
\hline F & & 12.279 & 7.668 & 6.206 & 3.901 & 3.294 & 1.000 \\
\hline $\mathrm{Na}$ & & 3.511 & 0.600 & 1.884 & 0.429 & 1.000 & 0.110 \\
\hline Vitamin C & & 8.160 & 1.062 & 4.422 & 0.873 & 2.347 & 0.224 \\
\hline Gallic acid & & 6.476 & 1.578 & 3.424 & 0.975 & 1.817 & 0.250 \\
\hline A & $\mathbf{A}_{1}$ & 6.788 & 3.256 & 0.128 & 0.063 & 1.844 & 0.437 \\
\hline $\mathbf{S}$ & $\mathbf{A}_{11}$ & 6.696 & 3.442 & 0.125 & 0.066 & 1.813 & 0.458 \\
\hline \multirow{3}{*}{ B } & $\mathbf{B}_{0}$ & 5.816 & 2.578 & 0.110 & 0.050 & 1.586 & 0.350 \\
\hline & $\mathbf{B}_{1}$ & 5.890 & 3.010 & 0.110 & 0.057 & 1.595 & 0.401 \\
\hline & $\mathrm{C}_{0}$ & 6.440 & 2.727 & 0.122 & 0.054 & 1.760 & 0.374 \\
\hline \multirow[t]{3}{*}{ C } & $\mathrm{C}_{1}$ & 6.386 & 3.131 & 0.120 & 0.060 & 1.733 & 0.419 \\
\hline & $\mathrm{C}_{2}$ & 6.576 & 3.395 & 0.123 & 0.065 & 1.780 & 3.149 \\
\hline & $\mathbf{D}_{0}$ & 6.354 & 2.674 & 0.120 & 0.053 & 1.737 & 0.367 \\
\hline \multirow{3}{*}{ D } & $\mathbf{D}_{2}$ & 6.574 & 3.243 & 0.123 & 0.062 & 1.783 & 0.434 \\
\hline & $\mathbf{D}_{1}$ & 6.382 & 3.011 & 0.120 & 0.058 & 1.734 & 0.405 \\
\hline & $\mathbf{D}_{11}$ & 6.395 & 2.951 & 0.120 & 0.057 & 1.740 & 0.399 \\
\hline \multirow{3}{*}{$\mathbf{E}$} & $\mathbf{E}_{0}$ & 6.290 & 2.646 & 0.119 & 0.052 & 1.719 & 0.363 \\
\hline & $\mathbf{E}_{2}$ & 6.470 & 3.150 & 0.122 & 0.061 & 1.756 & 0.422 \\
\hline & $\mathbf{F}_{0}$ & 6.653 & 3.311 & 0.125 & 0.063 & 1.804 & 0.442 \\
\hline \multirow[t]{3}{*}{$\mathbf{F}$} & $\mathbf{F}_{1}$ & 6.465 & 3.053 & 0.122 & 0.059 & 1.757 & 0.411 \\
\hline & $\mathbf{F}_{2}$ & - & - & - & - & - & - \\
\hline & $\mathbf{G}_{0}$ & 6.383 & 2.655 & 0.122 & 0.052 & 1.746 & 0.365 \\
\hline \multirow{3}{*}{ G } & $\mathbf{G}_{1}$ & 6.388 & 2.947 & 0.120 & 0.057 & 1.738 & 0.398 \\
\hline & $\mathbf{G}_{11}$ & 6.335 & 3.037 & 0.119 & 0.058 & 1.721 & 0.408 \\
\hline & $\mathbf{G}_{2}$ & 6.527 & 5.739 & 0.120 & 0.106 & 1.735 & 0.736 \\
\hline \multirow{3}{*}{ H } & $\mathbf{H}_{0}$ & 6.350 & 2.894 & 0.120 & 0.056 & 1.729 & 0.392 \\
\hline & $\mathbf{H}_{1}$ & 6.791 & 3.321 & 0.128 & 0.064 & 1.843 & 0.445 \\
\hline & $\mathbf{J}_{0}$ & - & - & - & - & - & - \\
\hline \multirow{3}{*}{ J } & $\mathbf{J}_{1}$ & - & - & - & - & - & - \\
\hline & $\mathbf{J}_{11}$ & - & - & - & - & - & - \\
\hline & $\mathbf{J}_{2}$ & - & - & - & - & - & - \\
\hline \multirow[t]{2}{*}{ K } & $\mathbf{K}_{0}$ & - & - & - & - & - & - \\
\hline & $\mathbf{L}_{0}$ & - & - & - & - & - & - \\
\hline \multirow{3}{*}{ L } & $\mathbf{L}_{1}$ & - & - & - & - & - & - \\
\hline & $\mathbf{L}_{11}$ & - & - & - & - & - & - \\
\hline & $\mathbf{L}_{2}$ & - & - & - & - & - & - \\
\hline \multirow{2}{*}{$\mathbf{M}$} & $\mathbf{M}_{0}$ & 6.293 & 2.719 & 0.119 & 0.053 & 1.718 & 0.371 \\
\hline & $\mathbf{M}_{1}$ & 6.397 & 3.029 & 0.120 & 0.058 & 1.739 & 0.408 \\
\hline \multirow{2}{*}{$\mathbf{N}$} & $\mathbf{N}_{0}$ & 6.329 & 0.099 & 0.120 & 0.053 & 1.729 & 0.369 \\
\hline & $\mathbf{N}_{1}$ & 6.364 & 2.976 & 0.106 & 0.057 & 1.539 & 0.401 \\
\hline \multirow{2}{*}{ O } & $\mathbf{O}_{0}$ & 6.489 & 4.013 & 0.121 & 0.075 & 1.743 & 0.524 \\
\hline & $\mathbf{O}_{1}$ & 6.607 & 3.178 & 0.124 & 0.061 & 1.794 & 0.427 \\
\hline $\mathbf{P}$ & $\mathbf{P}_{0}$ & 6.431 & 2.767 & 0.122 & 0.054 & 1.756 & 0.378 \\
\hline \multirow{3}{*}{ Q } & $\mathbf{Q}_{0}$ & - & - & - & - & - & - \\
\hline & $\mathbf{Q}_{1}$ & - & - & - & - & - & - \\
\hline & $\mathbf{R}_{0}$ & 6.745 & 3.176 & 0.127 & 0.061 & 1.834 & 0.428 \\
\hline \multirow[t]{2}{*}{$\mathbf{R}$} & $\mathbf{R}_{1}$ & 6.776 & 3.446 & 0.128 & 0.066 & 1.835 & 0.459 \\
\hline & $\mathbf{R}_{1}$ & 6.600 & 2.943 & 0.124 & 0.057 & 1.799 & 0.400 \\
\hline$S$ & $\mathrm{~S}_{0}$ & - & - & - & - & - & - \\
\hline \multicolumn{8}{|l|}{ Water } \\
\hline $\mathbf{F}$ & & 12.270 & 7.621 & 6.203 & 3.878 & 0.369 & 1.000 \\
\hline $\mathrm{Na}$ & & 30.001 & 0.390 & 16.803 & 1.998 & 1.000 & 0.515 \\
\hline Vitamin C & & 8.055 & 0.924 & 4.380 & 0.816 & 0.261 & 0.210 \\
\hline Gallic acid & & 6.480 & 1.687 & 3.416 & 1.019 & 0.203 & 0.263 \\
\hline A & $\mathbf{A}_{1}$ & 6.689 & 3.460 & 0.125 & 0.066 & 1.811 & 0.460 \\
\hline$S$ & $\mathbf{A}_{11}$ & 6.731 & 3.340 & 0.126 & 0.064 & 1.825 & 0.446 \\
\hline
\end{tabular}


TABle 5: Continued.

\begin{tabular}{|c|c|c|c|c|c|c|c|}
\hline Molecule & & $I$ & $A$ & $\omega^{-}$ & $\omega^{+}$ & $R_{\mathrm{d}}$ & $R_{\mathrm{a}}$ \\
\hline \multirow{2}{*}{ B } & $\mathbf{B}_{0}$ & - & - & - & - & - & - \\
\hline & $\mathbf{B}_{1}$ & 6.131 & 3.228 & 0.115 & 0.061 & 1.658 & 0.428 \\
\hline \multirow{3}{*}{ C } & $\mathrm{C}_{0}$ & 6.661 & 3.057 & 0.126 & 0.059 & 1.814 & 0.413 \\
\hline & $\mathrm{C}_{1}$ & 6.504 & 3.285 & 0.122 & 0.063 & 1.762 & 0.438 \\
\hline & $\mathrm{C}_{2}$ & 6.544 & 3.433 & 0.123 & 0.065 & 1.770 & 0.456 \\
\hline \multirow{4}{*}{ D } & $\mathbf{D}_{0}$ & - & - & - & - & - & - \\
\hline & $\mathbf{D}_{2}$ & - & - & - & - & - & - \\
\hline & $\mathbf{D}_{1}$ & - & - & - & - & - & - \\
\hline & $\mathbf{D}_{11}$ & - & - & - & - & - & - \\
\hline \multirow{2}{*}{$\mathbf{E}$} & $\mathbf{E}_{0}$ & - & - & - & - & - & - \\
\hline & $\mathbf{E}_{2}$ & - & - & - & - & - & - \\
\hline \multirow{3}{*}{$\mathbf{F}$} & $\mathbf{F}_{0}$ & 6.657 & 3.069 & 0.242 & 0.125 & 0.059 & 0.875 \\
\hline & $\mathbf{F}_{1}$ & 6.612 & 3.220 & 0.262 & 0.124 & 0.062 & 0.866 \\
\hline & $\mathbf{F}_{2}$ & 6.663 & 3.358 & 0.279 & 0.125 & 0.064 & 0.871 \\
\hline \multirow{4}{*}{ G } & $\mathbf{G}_{0}$ & 6.631 & 3.012 & 0.236 & 0.125 & 0.058 & 0.872 \\
\hline & $\mathbf{G}_{1}$ & 6.628 & 3.209 & 0.260 & 0.125 & 0.062 & 0.869 \\
\hline & $\mathbf{G}_{11}$ & 6.490 & 3.228 & 0.266 & 0.122 & 0.062 & 0.850 \\
\hline & $\mathbf{G}_{2}$ & 6.533 & 3.371 & 0.286 & 0.122 & 0.064 & 0.854 \\
\hline \multirow{3}{*}{$\mathbf{H}$} & $\mathbf{H}_{0}$ & - & - & - & - & - & - \\
\hline & $\mathbf{H}_{1}$ & - & - & - & - & - & - \\
\hline & $\mathbf{J}_{0}$ & 6.402 & 3.080 & 0.249 & 0.120 & 0.059 & 0.839 \\
\hline \multirow{3}{*}{$\mathbf{J}$} & $\mathbf{J}_{1}$ & 6.434 & 3.265 & 0.273 & 0.121 & 0.062 & 0.841 \\
\hline & $\mathbf{J}_{11}$ & 6.392 & 3.272 & 0.275 & 0.145 & 0.062 & 1.013 \\
\hline & $\mathbf{J}_{2}$ & 6.399 & 3.421 & 0.297 & 0.120 & 0.065 & 0.835 \\
\hline \multirow[t]{2}{*}{$\mathbf{K}$} & $\mathbf{K}_{0}$ & 6.803 & 3.198 & 0.255 & 0.128 & 0.062 & 0.893 \\
\hline & $\mathbf{L}_{0}$ & 6.421 & 3.111 & 0.252 & 0.121 & 0.060 & 0.841 \\
\hline \multirow{3}{*}{$\mathbf{L}$} & $\mathbf{L}_{1}$ & 6.408 & 3.301 & 0.279 & 0.120 & 0.059 & 0.837 \\
\hline & $\mathbf{L}_{11}$ & 6.409 & 3.301 & 0.279 & 0.120 & 0.063 & 0.838 \\
\hline & $\mathbf{L}_{2}$ & 6.425 & 3.454 & 0.302 & 0.120 & 0.066 & 0.838 \\
\hline \multirow{2}{*}{$\mathbf{M}$} & $\mathbf{M}_{0}$ & 6.417 & 2.953 & 0.233 & 0.121 & 0.057 & 0.843 \\
\hline & $\mathbf{M}_{1}$ & 6.455 & 3.161 & 0.258 & 0.121 & 0.061 & 0.846 \\
\hline \multirow{2}{*}{$\mathbf{N}$} & $\mathbf{N}_{0}$ & 6.468 & 2.993 & 0.237 & 0.122 & 0.058 & 0.850 \\
\hline & $\mathbf{N}_{1}$ & 6.487 & 3.183 & 0.260 & 0.122 & 0.061 & 0.850 \\
\hline \multirow{2}{*}{ O } & $\mathbf{O}_{0}$ & 6.620 & 3.232 & 0.263 & 0.124 & 0.062 & 0.867 \\
\hline & $\mathbf{O}_{1}$ & 6.625 & 3.247 & 0.265 & 0.124 & 0.062 & 0.868 \\
\hline $\mathbf{P}$ & $\mathbf{P}_{0}$ & 6.547 & 3.043 & 0.241 & 0.123 & 0.059 & 0.859 \\
\hline \multirow{3}{*}{ Q } & $\mathbf{Q}_{0}$ & 6.536 & 3.020 & 0.239 & 0.123 & 0.059 & 0.859 \\
\hline & $\mathbf{Q}_{1}$ & 6.541 & 3.195 & 0.260 & 0.123 & 0.061 & 0.857 \\
\hline & $\mathbf{R}_{0}$ & - & - & - & - & - & - \\
\hline \multirow[t]{2}{*}{$\mathbf{R}$} & $\mathbf{R}_{1}$ & 6.729 & 3.427 & 0.265 & 0.126 & 0.063 & 0.876 \\
\hline & $\mathbf{R}_{1}$ & 6.687 & 3.257 & 0.287 & 0.126 & 0.065 & 0.880 \\
\hline$S$ & $\mathrm{~S}_{0}$ & 6.527 & 3.079 & 0.246 & 0.123 & 0.060 & 0.857 \\
\hline
\end{tabular}

atoms: The difference between $R_{\mathrm{d}}$ value of $\mathrm{G}_{0}$ and that of $\mathrm{C}_{0}$ is equal to 0.0141 in the benefit of $\mathbf{C}_{0}$. The contribution of the integration of two hydrogen bonds $\left(\mathbf{O}_{6}-\mathbf{H} \ldots \mathbf{O}_{2}\right.$ and $\mathbf{O}_{10^{-}}$ $\left.\mathbf{H} . . \mathbf{O}_{2}\right)$ in this latter accentuates the antiradical behavior of $\mathrm{C}_{2}\left(R_{\mathrm{a}}=3.149\right)$ as electron acceptor. The electron donor capacity of $\mathbf{D}_{0}$ was compared to that of $\mathbf{G}_{0}$, where the 3methylbut-2-ene substituent at position 5 of anthraquinone system of the configuration $G$ and the methoxy group connected to $\mathbf{C}_{4}$ carbon atom are, respectively, replaced by 3,7-dimethyloct-2,6-diene substituent and the hydroxyl group. Those substitutions display a 0.0088 increase in $R_{\mathrm{d}}$ which signifies that the antiradical activity for $\mathbf{G}_{0}$ is worst. This can be attributed to the steric hindrance. Figure 6 exhibits the fact that the solvation increases the $R_{a}$ values of different anthraquinone derivatives examined. This therefore promotes the antiradical performance as good electron acceptor of the majority of compound analyzed compared to that of gallic acid and vitamin $\mathrm{C}$ with exception of the six molecules above mentioned $\left(\mathbf{A}_{11}, \mathbf{A}_{1}, \mathbf{C}_{0}, \mathbf{C}_{1}, \mathbf{C}_{2}\right.$, and $\left.\mathbf{B}_{1}\right)$. Our B3LYP calculations predict that $\mathbf{J}_{1}\left(R_{\mathrm{a}}=1.013\right.$ and $\left.R_{\mathrm{d}}=0.0624\right)$ is the best antiradical profile in water.

\section{Conclusion}

The geometrical optimizations of twenty anthraquinones extracted from the isolated from the Cameroonian flora have been performed at B3LYP/6-311++G(d,p) level of theory in gas phase and aqueous solutions. The topological analysis of optimized structures characterized by the formation of hydrogen bonds has been examined using the QTAIM (quantum theory of atom in the molecule) analysis. These hydrogen bond interactions are partially covalent because of the fact that $0.5<-\mathrm{G}(\mathrm{r}) / \mathrm{v}(\mathrm{r})<1$. In addition, the nature of these interactions has shown to be influenced by the chain effect of the substituent.

The stability of the molecular system has been developed in thermodynamic and kinetic points of view. In the first point of view, the total energy has been adopted as descriptor. The configuration preferences dominated by the number of hydrogen bonds is very visible. The great augmentation of dipole moment provoked by the change of the environment is related to greater dielectric constant of water $(\varepsilon=78.4)$. In the second point of view, the HOMO-LUMO energy gap has been used as descriptor in the first stage. The 1,8-dihydroxy-2-(3-methylbut-1-en)-3-methoxy-6-methylanthraquinone $\left(\mathbf{B}_{0}\right)$ in the configuration bearing one hydrogen bond is the less stable due to its lowest value of HOMO-LUMO energy gap $(2.880 \mathrm{eV})$. The $0.358 \mathrm{eV}$ difference in HOMO-LUMO energy gap between this configuration and that without hydrogen bond confirms the sensitive contribution of hydrogen bond on the stability. The aqueous solvation leads to the diminution of the band gap values that traduce the diminution of the stability. The highest $\eta$ value in various media observed (1.864 and $1.810 \mathrm{eV}$, respectively, in gas phase and water) for the 1,8 dihydroxy-2-(3-methylbut-2-en)-3-methoxy-6-methyl-anthraquinone $\left(\mathbf{G}_{0}\right)$ without hydrogen bond indicates that this configuration is kinetically the most stable. This confirms the result obtained by both thermodynamic approaches. This confirmation observed for $\mathbf{G}_{0}$ elected using highest HOMO-LUMO energy gap criteria and that $\left(\mathbf{G}_{0}\right)$ selected from highest $\eta$ value exigence shows that the discontinuity problems claimed by Geerlings et al. [20] are due to the lack of an integration of kinetic energy, exchange, and correlation parts into the classical Coulombic fragment in the Hohenberg-Kohn universal density functional.

Our B3LYP results demonstrate that the 1,8-dihydroxy2-(3-methylbut-1-en)-3-methoxy-6-methyl-anthraquinone $\left(\mathbf{B}_{0}\right)$ is the most antioxidant compounds due to its relatively lowest IP value $(5.816 \mathrm{eV})$ in gas phase. The SET mechanism is more prominent for compounds of the molecular library analyzed than for classical phenolic acids (gallic acid, caffeic acid, and ferulic acid at the B3LYP/6$311++\mathrm{G}(\mathrm{d}, \mathrm{p})$ level $)$ and ascorbic acid. In the same vein, the 
compounds examined have shown to be higher antiradical behavior as electron donor with respect to the electron capacity of vitamin $\mathrm{C}$ and gallic acid in gas phase with exception for four compounds $\mathbf{A}_{1}$ (4-(carbonyl)-3-hydroxy-1-methoxy-anthraquinone), $\mathbf{H}_{1}$ (1,3,5-trihydroxy-3methoxycarbonylanthraquinone), $\mathbf{R}_{0}$, and $\mathbf{R}_{1}$ (7-(carboxyl)$(3,6)$-dimethoxy-8-methyl-1-hydroxyanthraquinone)) in the latter case. In water, 5,8-dihydroxy-3-methylanthraquinone structure with one hydrogen bond $\left(\mathrm{J}_{1}\right.$ : $R_{\mathrm{a}}=1.013$ and $\left.R_{\mathrm{d}}=0.0624\right)$ has been predicted as the best antiradical compound.

\section{Data Availability}

The data used to support the findings of this study are available from the corresponding author upon request.

\section{Conflicts of Interest}

The authors declare that they have no conflicts of interest.

\section{Acknowledgments}

The authors are grateful to Dr. Cyril Assongo Kenfack (Cepamoq, University of Douala, Cameroon) for helpful discussion. Scientific support and access to computing resources from the High Performance Computing Center of the University of Strasbourg (funded by Equipex: Programme d'investissements d'Avenir) are also gratefully acknowledged. This work was supported by the Ministry of Higher Education of Cameroon.

\section{References}

[1] H. S. Kim and K. B. Chin, "Antioxidant activity of tomato powders as affected by water solubility and application to the pork sausages," Korean Journal for Food Science of Animal Resources, vol. 33, no. 2, pp. 170-180, 2013.

[2] K. M. Desai, T. Chang, H. Wang et al., "Oxidative stress and aging: is methylglyoxal the hidden enemy?," Canadian Journal of Physiology and Pharmacology, vol. 88, no. 3, pp. 274-284, 2010.

[3] H. Cao, W.-X. Cheng, C. Li, X.-L. Pan, X.-G. Xie, and T.-H. Li, "DFT study on the antioxidant activity of rosmarinic acid," Journal of Molecular Structure: THEOCHEM, vol. 719, no. 1-3, pp. 177-183, 2005.

[4] V. Lobo, A. Patil, A. Phatak, and N. Chandra, "Free radicals, antioxidants and functional foods: impact on human health," Pharmacognosy Reviews, vol. 4, no. 8, pp. 118-126, 2010.

[5] J. Kocot, D. Luchowska-Kocot, M. Kiełczykowska, I. Musik, and J. Kurzepa, "Does vitamin C influence neurodegenerative diseases and psychiatric disorders?," Nutrients, vol. 9, no. 7, p. 659, 2017.

[6] M. Shamsipur, K. Alizadeh, and S. Arshadi, "Computational electrochemistry of aqueous two-electron reduction potentials of some amino-9,10-anthraquinone derivatives," Journal of Molecular Structure: THEOCHEM, vol. 758, no. 1, pp. 7174, 2006.

[7] H. Greige-Gerges, Y. Diab, J. Farah, J. Magdalou, C. Haddad, and N. Ouaini, "Ferutinin stability in human plasma and interaction with human serum albumin," Biopharmaceutics \& Drug Disposition, vol. 29, no. 2, pp. 83-89, 2008.
[8] M. Zavatti, C. Montanari, and P. Zanoli, "Role of ferutinin in the impairment of female function induced by Ferula hermonis," Physiology and Behavior, vol. 89, no. 5, pp. 659-661, 2006.

[9] W. Nam, S. P. Kim, S. H. Nam, and M. Friedman, "Structureantioxidative and anti inflammatory activity relationships of purpurin and related anthraquinones in chemical and cell assays," Molecules, vol. 22, no. 2, p. E265, 2017.

[10] K. E. Malterud, T. L. Farbrot, A. E. Huse, and R. B. Sund, "Antioxidant and radical scavenging effects of anthraquinones and anthrones," Pharmacology, vol. 47, no. 1, pp. 77-85, 1993.

[11] D. Özbakır Işın, "Theoretical study on the investigation of antioxidant properties of some hydroxyanthraquinones," Molecular Physics, vol. 114, no. 24, pp. 3578-3588, 2016.

[12] J. M. D. Markovic, B. Pejin, D. Milenkovic et al., "Antiradical activity of delphinidin, pelargonidin and malvin towards hydroxyl and nitric oxide radicals: the energy requirements calculations as a prediction of the possible antiradical mechanisms," Food Chemistry, vol. 218, pp. 440-446, 2017.

[13] E. Abraham and Sisein, "Biochemistry of free radicals and antioxidants," Scholars Academic Journal Biosciences, vol. 2, no. 2, pp. 110-118, 2014.

[14] M. J. Frisch, G. W. Trucks, H. B. Schlegel et al., Gaussian 09: Revision A.2, Gaussian, Inc., Wallingford CT, UK, 2009.

[15] T. Lu and F. Chen, "Multiwfn: a multifunctional wavefunction analyzer," Journal of Computational Chemistry, vol. 33, no. 5, pp. 580-592, 2012.

[16] S. Jenkins, Z. Liu, and S. R. Kirk, "A bond, ring and cage resolved Poincaré-Holf relationship for isomerization pathways," Molecular Physics: An international Journal at the Interface between Chemistry and Physics, vol. 111, no. 20, pp. 1-14, 2013.

[17] E. Espinosa, E. Molins, and C. Lecomte, "Hydrogen bond strengths revealed by topological analyses of experimentally observed electron densities," Chemical Physics Letters, vol. 285, no. 3-4, pp. 170-173, 1998.

[18] R. S. Borges, A. S. Carneiro, T. G. Barros, C. A. L. Barros, A. M. J. Chaves Neto, and A. B. F. Das Silva, "Understanding the cytotoxicity or cytopropective effects of biological and synthetic quinone derivatives by redox mechanism," Journal of Molecular Modeling, vol. 20, no. 12, pp. 2541-2549, 2014.

[19] R. S. Borges, J. P. Oliveira, R. F. Matos, A. M. Chaves Neto, A. S. Carneiro, and M. C. Monteiro, "Involvement of electron and hydrogen transfer through redox metabolism on activity and toxicity of the nimesulide," Journal of Molecular Modeling, vol. 21, no. 7, pp. 2712-2717, 2015.

[20] P. Geerlings, F. De Proft, and W. Langenaeker, "Conceptual density functional theory," Chemical Reviews, vol. 103, no. 5, pp. 1793-1874, 2003.

[21] J. L. Gázquez, A. Cedillo, and A. Vela, "Electrodonating and electroaccepting powers," Journal of Physical Chemistry A, vol. 111, no. 10, pp. 1966-1970, 2007.

[22] A. Martinez, A. M. Rodriguez-Gironé, A. Barbosa, and M. Costas, "Donator acceptor map for carotenoids, melatonin and vitamins," Journal of Physical Chemistry. A, vol. 112, no. 38, pp. 9037-9042, 2008.

[23] T. Steiner, "The hydrogen bond in the solid state," Angewandte Chemie International Edition, vol. 41, no. 1, pp. 48-76, 2002.

[24] R. G. Parr, L. V. Szentpály, and S. Liu, "Electrophilicity index," Journal of the American Chemical Society, vol. 121, no. 9, pp. 1922-1924, 1999. 
[25] F. De Proft and P. Geerlings, "Contribution of the shape factor $\sigma(\mathrm{r})$ to atomic and molecular electronegativities," Journal of Physical Chemistry A, vol. 101, no. 29, pp. 5344-5346, 1997.

[26] H.-Y. Zang, "Structure-activity relationships and rational design strategies for radical-scavenging antioxidants," Current Computer-Aided Drug Design, vol. 1, pp. 257-273, 2005.

[27] R. Jin, "A DFT study on the radical scavenging activity of juglone and its derivatives," Journal of Molecular Structure: THEOCHEM, vol. 939, no. 1-3, pp. 9-13, 2010.

[28] M. Salga, I. Sada, and A. Mustapha, "Influence of steric hindrance on the antioxidant activity of some Schiff base ligands and their copper(II) complexes," Oriental Journal of Chemistry, vol. 30, no. 4, pp. 1529-1534, 2014.

[29] R. Amorati, M. Lucarini, V. Mugnaini, and G. F. Pedulli, "Antioxidant activity ofo-bisphenols: the role of intramolecular hydrogen bonding," Journal of Organic Chemistry, vol. 68, no. 13, pp. 5198-5204, 2003.

[30] X. Yunsheng, Z. Youguang, A. Lin, D. Yunyan, and L. Yi, "Density functional theory of the structure-antioxidant activity of polyphenolic deoxybenzoins," Journal of Food Chemistry, vol. 151, pp. 198-206, 2014.

[31] Y. Chen, H. Xiao, J. Zheng, and G. Liang, "Structure thermodynamics-antioxidant activity relationships of selected natural phenolic acids and derivatives: an experimental and theoretical evaluation," PLoS One, vol. 10, no. 3, Article ID e0121276, 2015. 

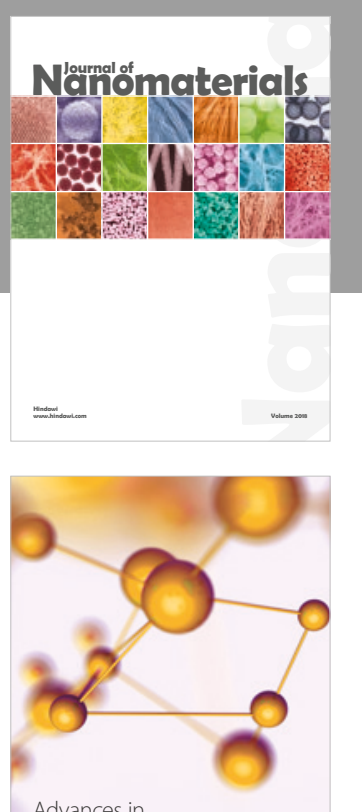

Physical Chemistry
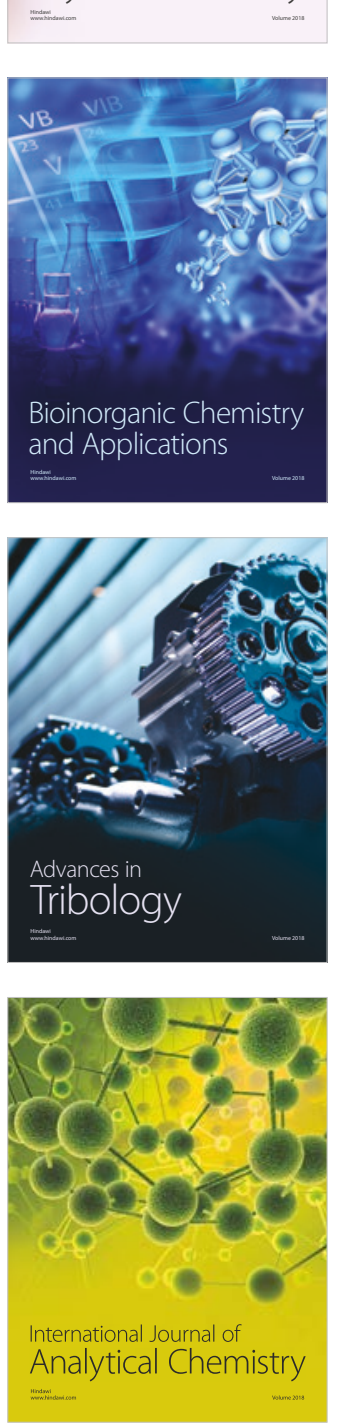

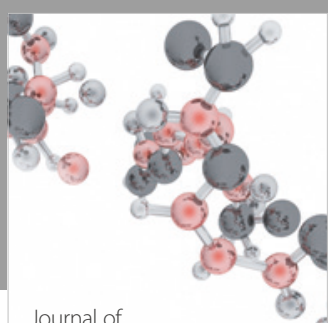

Analytical Methods

in Chemistry

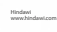

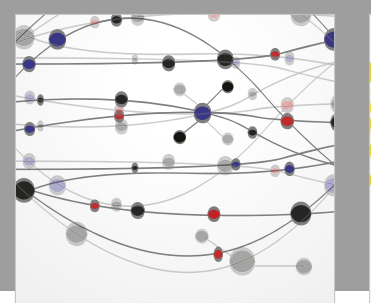

The Scientific World Journal

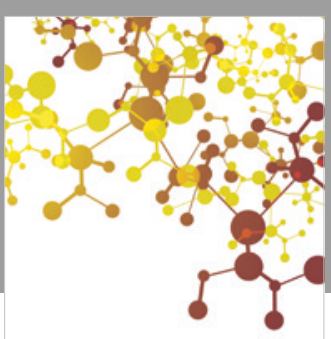

Journal of

Applied Chemistry
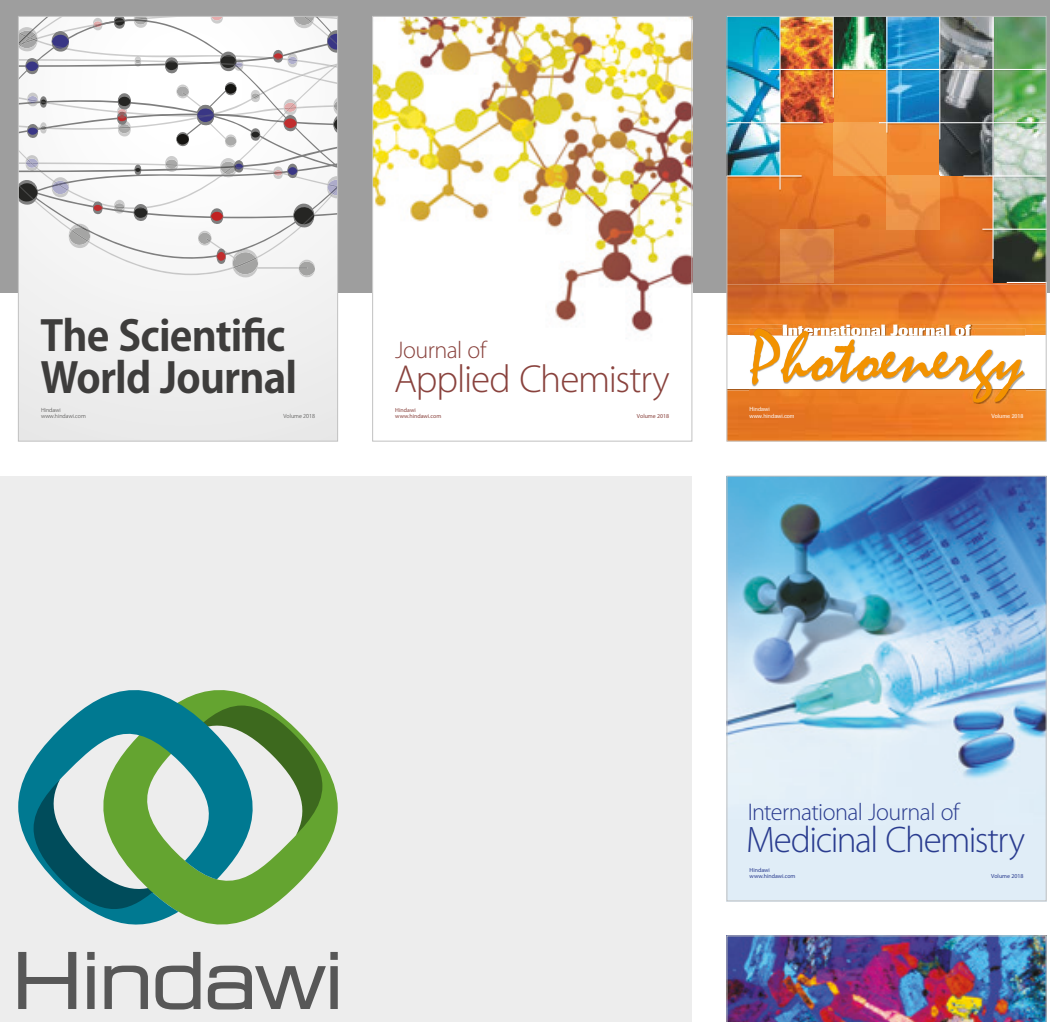

Submit your manuscripts at

www.hindawi.com
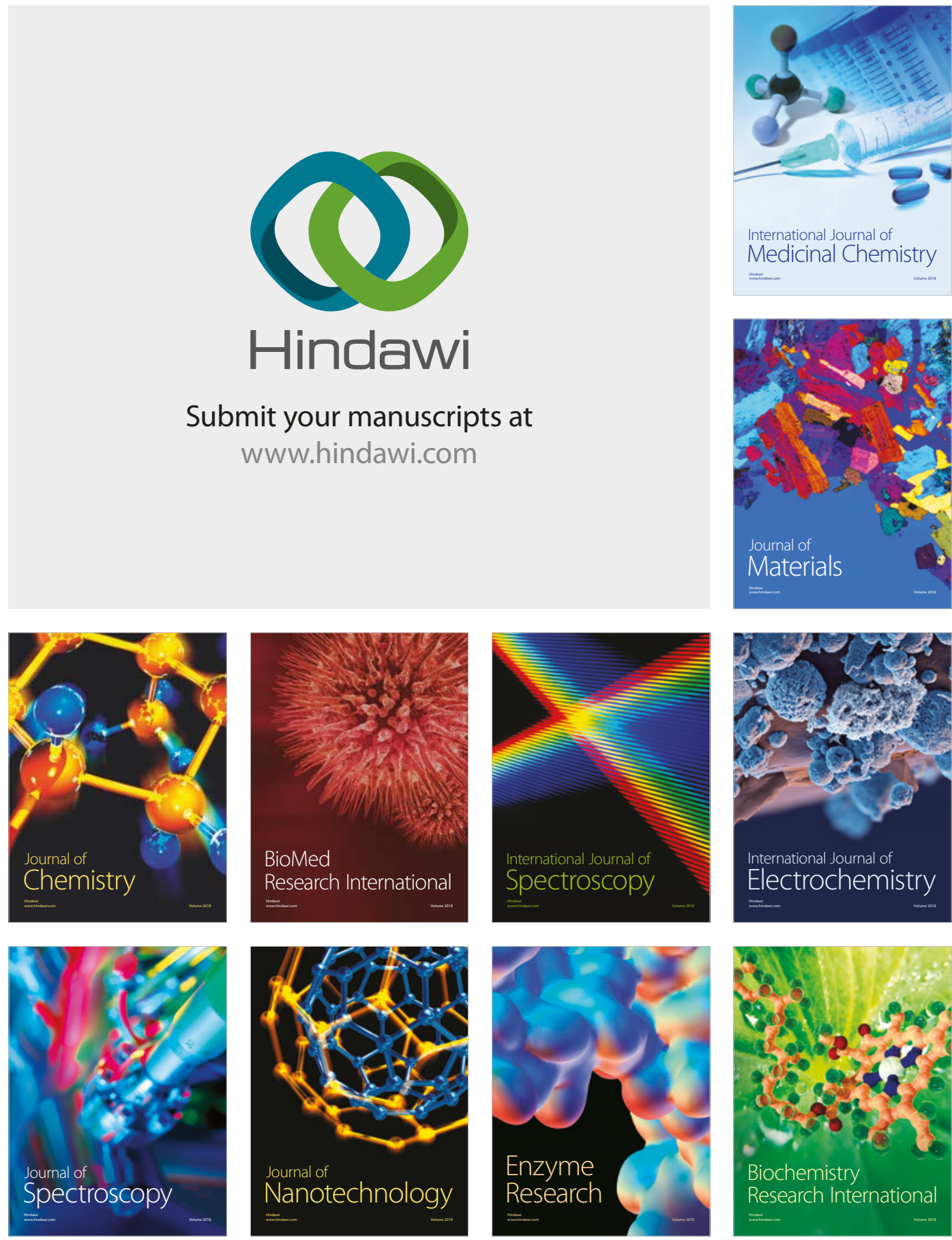
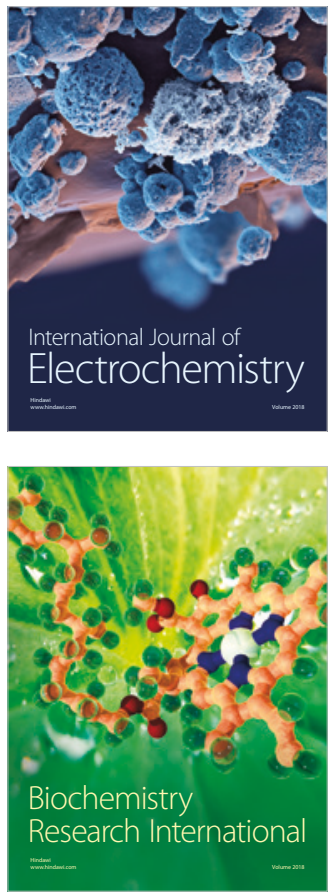